Anais da VI Mesa Redonda de Mortalidade Materna e II Simpósio de Enfermagem Obstétrica. 2019; 09-67

\title{
ANAIS DA VI MESA REDONDA DE MORTALIDADE MATERNA E II SIMPÓSIO DE ENFERMAGEM OBSTÉTRICA
}

\section{Organização:}

Residência em Enfermagem Obstétrica da UEL

\section{Apoio:}

\section{ACERVO Meploriviscas}

As publicações mais rápidas do país!

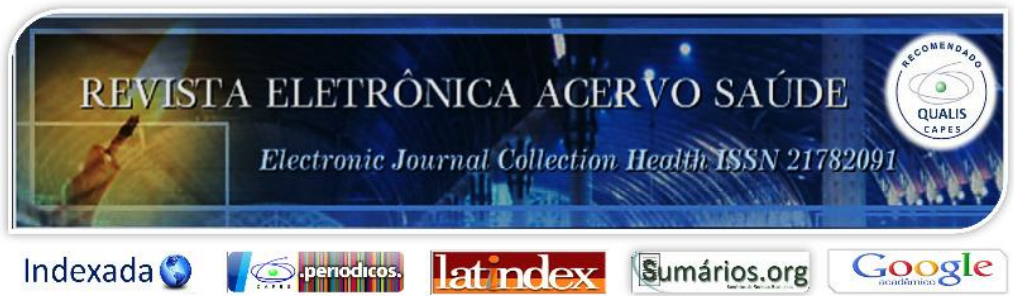


Anais da VI Mesa Redonda de Mortalidade Materna e II Simpósio de Enfermagem Obstétrica. 2019; 8-45.

\section{Apoiadores do Evento}

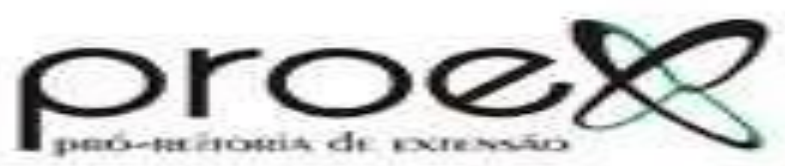

\section{Patrocinadores do Evento}
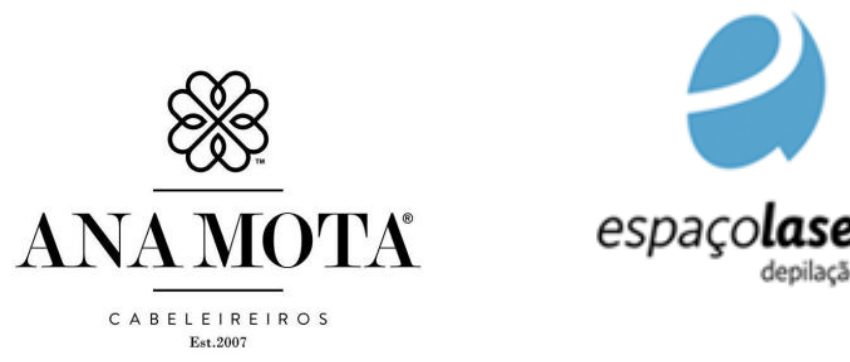

Wy $\underset{\text { bearson }}{W}$ ARD

espaçolaser

depilaçăo 
Anais da VI Mesa Redonda de Mortalidade Materna e II Simpósio de Enfermagem Obstétrica. 2019; 8-45.

\section{COMISSÃO ORGANIZADORA}

- Aline do Nascimento de Andrade

- Cassia Macena

- Catia Campaner Ferrari Bernardy

- Daniela Biguetti Martins Lopes

- Eliseth Krupa Almeida

- Gabriela Souza Alves Fraron

- Giovanna Moreira de Pontes

- Keli Regiane Tomeleri da Fonseca Pinto

- Jossane Julie Pereira

- Juliana Sousa de Almeida

- Laís de Lima Oliva

- Larissa Pereira Falavina

- Maria Elisa Wotzasek Cestari

- Natália Carolina Rodrigues Colombo

- Nathalia Jung Ferreira

- Renata Portero Wielganczuk

- Thelma Malagutti Sodré

- Wallans Messias Ortiz da Silva

- Yasmin Duque Franco

\section{COMISSÃO CIENTÍFICA}

- Catia Campaner Ferrari Bernardy

- Daniela Biguetti Martins Lopes

- Keli Regiane Tomeleri da Fonseca Pinto

- Maria Elisa Wotzasek Cestari

- Natália Carolina Rodrigues Colombo

- Thelma Malagutti Sodré 
Anais da VI Mesa Redonda de Mortalidade Materna e II Simpósio de Enfermagem Obstétrica. 2019; 8-45.

\section{Apresentação}

Para garantir mais acesso, cuidado, informação e saúde à mulher brasileira, o Ministério da Saúde instituiu a Semana de Mobilização Nacional pela Saúde das Mulheres.

O dia 28 de maio é de extrema importância, pois esta data marca duas lutas para a saúde feminina, o Dia Internacional de Luta Pela Saúde da Mulher e o Dia Nacional de Redução da Mortalidade Materna. Ambas têm como objetivo chamar a atenção e conscientizar a sociedade dos diversos problemas de saúde e distúrbios comuns na vida das mulheres.

Buscando comemorar essa data, foi realizada a VI Mesa Redonda de Mortalidade Materna e II Simpósio de Enfermagem Obstétrica no dia 29 de maio de 2019, no Centro de Ciências da Saúde da Universidade Estadual de Londrina, uma realização do Programa de Residência em Enfermagem Obstétrica, da área "Saúde da Mulher e Gênero", do Departamento de Enfermagem da Universidade Estadual de Londrina (UEL).

O evento teve como objetivo promover discussões sobre a saúde da mulher e as medidas de prevenção da mortalidade materna. O público-alvo foi composto por estudantes, docentes, profissionais de saúde, instituições e grupos sociais envolvidos com a saúde da mulher e teve a participação de 120 pessoas.

Parabenizamos a todos os autores pelo empenho e dedicação, foram recebidos 37 resumos de trabalhos, os quais foram compilados e estão publicados nessa edição da Revista Eletrônica Acervo Científico como Anais da VI Mesa Redonda de Mortalidade Materna e II Simpósio de Enfermagem Obstétrica. 
Anais da VI Mesa Redonda de Mortalidade Materna e II Simpósio de Enfermagem Obstétrica. 2019; 8-45.

\section{PROGRAMAÇÃo}

8h00 - 8h30 - Recepção

8h30 - 8h45 - Abertura

8h45 - 9h25 - Perfil da Mortalidade Materno no Norte do Paraná Enf. a Michele Patrícia Amadeu - Comitê Municipal de Prevenção da Mortalidade Materno Infantil

9h30 - 10h10 - Pré-natal: novas perspectivas para melhorar a qualidade da assistência

Enf. ${ }^{\text {a }}$ Dda. Fabiana Fontana Medeiros - Enfermeira Obstetra, Departamento de Enfermagem da UEL.

10h15 - 10h40 - Coffee Break

10h45 - 11h45 - Atendimento a gestantes em situação de rua

Psicóloga Sarah G. Toninato - Consultório de Rua - Secretaria de Saúde de Londrina

$12 \mathrm{~h} 00$ - $13 \mathrm{~h} 30$ - Almoço

13h30 - 14h40 - Avaliação de trabalhos científicos na modalidade pôster

14h00 - 14h45 - Cesárea: o desafio de reduzir indicações

Médica Obstetra Flávia R. Motta Zanoni Albernaz

15h00 - 15h15 - Intervalo

15h15 - 17h00 - Mesa Redonda: experiência de enfermeiras obstétricas na atenção ao parto

Camila Moscardini de Aquino Rosa - Hospital São Rafael de Rolândia

Nara de Morais Lima - Santa Casa de Cambé

Juliana Carvalho Lourenço - Hospital Evangélico de Londrina

Ana Olympia Velloso Marcondes Dornellas - Maternidade Municipal de

Londrina

Karen Gomes - Hospital Universitário de Londrina

$17 \mathrm{~h} 00$ - 17h30 - Debate

17h30 - 18h00 - Sorteio de brindes, premiação dos trabalhos e encerramento. 
Anais da VI Mesa Redonda de Mortalidade Materna e II Simpósio de Enfermagem Obstétrica. 2019; 09-67.

\section{Sumário}

1 Estratégias de humanização para adesão da nova recomendação do manual 9 de suplementação de sulfato ferroso.

2 Perfil epidemiológico e acompanhamento nutricional gestacional: uma visão 11 multiprofissional.

3 Realização de exames sorológicos para sífilis durante a gestação.

4 Indução do trabalho de parto de gestantes em maternidades públicas de 15 Londrina/PR.

5 Utilização de terapias não farmacológicas em maternidades de pequeno 16 porte no Norte do Paraná.

6 O uso de métodos anticoncepcionais e gravidez não planejada em gestantes 17 de alto risco.

7 Perfil e taxa de incidência de gestantes com sífilis no Brasil nos últimos dez 19 anos.

8 Principais causas de óbitos maternos em um estado brasileiro no período de 20 2112 a 2016.

9 Métodos terapêuticos utilizados em traumas mamilares de puérperas em uma 21 maternidade de alto risco.

10 Perfil de atividade física de mulheres gestantes do Hospital das Clínicas.

11 Efeitos do treinamento resistido sobre a força muscular, composição corporal 24 e indicadores cardiometabólicos de mulheres.

12 Análise da assistência pré-natal em um município com implementação da 26 Rede Mãe Paranaense.

13 Satisfação da puérpera com a assistência em uma maternidade de alto risco. 28

14 Rastreamento do consumo de álcool durante o pré-natal realizado na 29 atenção básica.

15 A vivência do parto normal: percepção e satisfação das puérperas.

16 Atuação de residentes de enfermagem obstétrica em um grupo de gestantes: 33 relato de experiência.

17 Atuação de residentes de enfermagem obstétrica em um grupo de gestantes: 35 relato de experiência.

18 Orientações sobre amamentação para um grupo de gestante: relato de 37 experiência.

19 Educação em saúde sobre o autoexame das mamas: relato de experiência. 39

20 Conhecimento a partir da extensão universitária: relato de experiência. 41

21 Projeto de extensão Visita à maternidade: relato de experiência. 42

22 Relato de experiência sobre estágio extracurricular em uma maternidade de 43 alto risco.

23 Atividade extensionista: o significado para o aluno da graduação. 44

24 Consulta de pré-natal por enfermeiras residentes: relato de experiência. $\quad 45$ 
Anais da VI Mesa Redonda de Mortalidade Materna e II Simpósio de Enfermagem Obstétrica. 2019; 09-67.

25 Inserção do discente do curso de Enfermagem na promoção do cuidado 47 canguru: relato de experiência.

26 A multidisciplinaridade do planejamento reprodutivo na Unidade Básica de 49 Saúde.

27 Uso de medicamentos na gravidez, no puerpério e na lactação: o 51 farmacêutico na avaliação de riscos.

28 A vivência de estudantes de Enfermagem em uma maternidade pública: 52 relato de experiência.

29 Consulta compartilhada e o cuidado integral à saúde da mulher: relato de 53 experiência.

30 Relato de experiência: contato pele a pele no puerpério imediato.

31 Relato de experiência: educação em saúde para prevenção de câncer de colo 56 de útero.

32 Sífilis congênita decorrente de reinfecção da gestante devido à não adesão 57 do parceiro ao tratamento.

33 A violência obstétrica representada no cotidiano institucional: uma revisão 58 integrativa.

34 Assistência de enfermagem durante o trabalho de parto: métodos não 60 farmacológicos para alívio da dor.

35 O impacto da retirada do termo "violência obstétrica" no ensino.

36 Principais determinantes de Near Miss materno que levam puérperas a uma 65 UTI obstétrica: revisão integrativa.

37 O cuidado centrado na família na Unidade de Terapia Intensiva Neonatal: 67 foco no método canguru. 
RESUMOS 


\title{
1. ESTRATÉGIAS DE HUMANIZAÇÃO PARA ADESÃO DA NOVA RECOMENDAÇÃO DO MANUAL DE SUPLEMENTAÇÃO DE SULFATO FERROSO
}

\author{
Dayse Kellen de Sousa Santos*, Tatiane Tokushima, Natana Evelyn Andreassi,
} Roberta Paiva, Clísia Mara Carreira

*Universidade Estadual de Londrina, Londrina-PR, e mail: daysekellen@hotmail.com.br

INTRODUÇÃO: A anemia Ferropriva atualmente é considerada problema de saúde pública no Brasil pela alta prevalência entre gestantes, frente a este agravante 0 Ministério da Saúde do Brasil criou o Programa Nacional de Suplementação de Ferro em 2005, este preconizava a administração profilática de Sulfato Ferroso após a 20a semana de gestação. Em 2013 este manual foi atualizado e a partir de então preconizou-se que a suplementação deveria ocorrer para todas as gestantes em acompanhamento pré-natal independentemente da idade gestacional e devendo permanecer até o terceiro mês pós-parto. OBJETIVO: Tem-se como objetivo criar estratégias de adesão ao novo tratamento por meio do atendimento multiprofissional e acolhimento humanizado. MÉTODO: Durante as visitas domiciliares os profissionais ouviram as dificuldades relatadas e esclareciam sobre a importância da suplementação do ferro para a saúde da mãe e do bebê. Tratou-se de um estudo transversal, com amostragem aleatória, realizado no período de março a julho de 2015 na cidade de Londrina no Paraná. Em questionário específico anotava-se as informações coletadas. A análise de dados se fez a partir das respostas contidas nos questionários. Os profissionais questionavam sobre qual o motivo da não adesão a suplementação e ouviam as dificuldades relatadas demonstrando compreensão e acolhimento. Logo em seguida estes tomavam a fala e esclareciam quanto a necessidade de continuidade da suplementação, sendo que a nutricionista esclarecia sobre os aspectos nutricionais da deficiência, as enfermeiras, as manifestações clínicas, e a farmacêutica sobre as novas possibilidades de ingestão como por exemplo a alteração do momento da ingestão. RESULTADOS: Quando questionadas sobre a não adesão a suplementação, as pacientes referem intolerância ao medicamento com citações de enjoos e dores estomacais, sendo estes sintomas também ocorridos com a suplementação durante a gestação. As puérperas também esclareciam que não haviam sido informadas pelos profissionais de acompanhamento do parto e puerpério imediato, sobre a necessidade da suplementação de sulfato ferroso no pós-parto, sendo que muitas delas inclusive não apresentavam receita para recebimento dos comprimidos pela farmácia da Unidade Básica de Saúde em que se havia recebido a assistência pré-natal; tal fato ocorre devido a desinformação dos profissionais de saúde, que possivelmente desconhecem a atualização do manual e não fazem a prescrição do medicamento no período puerperal. CONCLUSÃO: Com essa nova estratégia de humanização na visita domiciliar, percebeu-se que a falta de adesão a nova suplementação de sulfato ferroso preconizada pelo Ministério da Saúde do Brasil está relacionada com a intolerância da paciente ao medicamento e principalmente a desinformação dos profissionais de saúde, que possivelmente desconhecem a atualização do manual e não fazem a prescrição do medicamento corretamente.

DESCRITORES: Gestantes; Suplementação; Sulfato Ferroso. 


\section{REFERÊNCIAS}

Brasil. Ministério da Saúde. Secretaria de Atenção à Saúde. Departamento de Atenção Básica. Programa Nacional de Suplementação de Ferro: manual de condutas gerais / Ministério da Saúde. Secretaria de Atenção à Saúde. Departamento de Atenção Básica. Brasília: Ministério da Saúde, 2013. 24 p.

Brasil. Ministério da Saúde. Secretaria de Atenção à Saúde. Departamento de Atenção Básica. Manual operacional do Programa Nacional de Suplementação de Ferro / Ministério da Saúde, Secretaria de Atenção à Saúde, Departamento de Atenção Básica. - Brasília: Ministério da Saúde, 2005. 28p. (Série A. Normas e Manuais Técnicos). 


\section{PERFIL EPIDEMIOLOGICO E ACOMPANHAMENTO NUTRICIONAL GESTACIONAL: UMA VISÃO MULTIPROFISSIONAL}

Dayse Kellen de Sousa Santos*, Daiane de Lisboa Mendes do Prado, Roberta Paiva, Clísia Mara Carreira, Edilaine Baccarin Petenuci

*Universidade Estadual de Londrina, Londrina-PR, e
daysekellen@hotmail.com.br

INTRODUÇÃO: A assistência pré-natal tem relação estreita com o estado de saúde das mães e seus filhos, a ausência ou a baixa qualidade desta assistência está associada as altas taxas de morbimortalidade materno infantil e inadequadas condições de nascimento. OBJETIVO: discutir na visão do nutricionista, psicólogo e farmacêutico os resultados obstétricos indesejáveis e sua relação com o perfil epidemiológico tais como: gestação na adolescência, desvios nutricionais gravídicos e gestacionais, renda, raça e escolaridade. MÉTODO: Tratou-se de uma pesquisa de cunho transversal, de amostragem aleatória de 80 gestantes que realizaram seu prénatal entre março de 2015 a março de 2016, em duas unidades básicas de saúde em Londrina-PR nas quais trabalhava a equipe da residência multiprofissional de Saúde da Mulher; após aprovação do comitê de ética com o número 1.428.379, iniciou-se a coleta de dados em portuários; A evolução nutricional gestacional avaliou-se conforme metodologia preconizado pelo Ministério da Saúde. RESULTADOS: Em relação a faixa etária a triagem realizada detectou que $20 \%$ das gestantes eram adolescentes; $51 \%$ das gestantes apresentava renda familiar de até 3 salários mínimo e $9 \%$ até meio salário mínimo. 24\% recebiam benefício governamental; apenas $28 \%$ das gestantes tinha ensino médio completo; $20 \%$ eram negras e $41 \%$ não exerciam atividade remunerada. Em relação a evolução nutricional 31\% das gestantes mantiveram-se na faixa de adequado; $24 \%$ iniciaram a gestação em sobrepeso e não evoluíram desfavoravelmente para obesidade, mantiveram-se no sobrepeso, conforme é preconizado pelo Ministério da Saúde para a gestação que se inicia em sobrepeso, tal fato retrata a importância do nutricionista, no acompanhamento do pré-natal. 14\% das gestantes que iniciaram a gestação em baixo peso evoluíram até o termo em baixo peso, destas $40 \%$ são adolescentes, explicitando assim a relação já conhecida entre a evolução nutricional gestacional inadequada e gestação na adolescência, justificada pelas características nutricionais peculiares desta faixa etária. Tais dados reforçam também a necessidade de atuação dos profissionais de saúde aprimorando atividades de educação sexual voltadas para este público, bem como o trabalho psicossocial envolvido que dê conta de acolher e ressignificar as múltiplas dimensões e sentidos de ser ter um filho na adolescência. CONCLUSÃO: Quando há a assistência multiprofissional adequada no pré-natal há melhor qualidade no pré-natal e consequentemente melhores condições de parto e nascimento, fato este que relacionase intrinsecamente aos índices de morbimortalidade materno-infantil.

DESCRITORES: Gestação; Nutrição; Adolescência.

\section{REFERÊNCIAS}

SALVADOR, B. C.; PAULA, H. A. A.; SOUZA, C. C.; COSTA, A. M.; BATISTA, M. A.; PIRES, R. C. et al. Atenção pré-natal em Viçosa-MG: contribuições para discussão de políticas de saúde. Revista Medica. v. 18, n. 3, p. 167-174, 2008. 


\section{Obstétrica,2019;09-67}

VIGILÂNCIA ALIMENTAR E NUTRICIONAL - Sisvan: orientações básicas para a coleta, processamento, análise de dados e informação em serviços de saúde / [Andhressa Araújo Fagundes et al.]. - Brasília: Ministério da Saúde, 2004. 120 p.

BELARMino, G. O. MOURA, E. R. F. OliVeIRA, N. C.; FREITAS, G. L. Risco nutricional entre gestantes adolescentes. Acta Paulista de Enfermagem. v. 22, n. 2, p. 169-175, 2009. 


\section{REALIZAÇÃO DE EXAMES SOROLÓGICOS PARA SÍFILIS DURANTE A GESTAÇÃO}

Kawany de Paula Lima*, Pamela Panas dos Santos Oliveira, Maria Caroline Rogério, Luana da Silva, Keli Regiane Tomeleri da Fonseca Pinto

*Universidade Estadual de Londrina, Londrina- PR, e mail: kawany-hs@hotmail.com

INTRODUÇÃO: A sífilis é uma doença infecciosa de evolução crônica causado pelo agente etiológico Treponema pallidum. A forma congênita da doença é responsável por altos índices de desenvolvimento de comorbidades pelo feto, como o abortamento espontâneo, morte fetal ou neonatal, prematuridade e graves danos á saúde do concepto, como o comprometimento oftalmológico, auditivo e neurológico. 0 diagnóstico de sífilis deve ser realizado durante o pré-natal, através dos exames sorológicos como o VDRL e o FTA-Abs na primeira consulta, ainda no $1^{\circ}$ trimestre e no $3^{\circ}$ trimestre da gestação. OBJETIVO: Identificar a realização dos exames sorológicos para sífilis em gestantes. MÉTODO: Trata-se de um recorte da pesquisa "Rede Mãe Paranaense na perspectiva da usuária: o cuidado da mulher no pré-natal, parto, puerpério e da criança", cadastrada na PROPPG n. 10735 e aprovada na Chamada Universal MCTI/CNPq $\mathrm{n}^{\circ}$ 01/2016, realizada em maternidades de pequeno porte da $17^{\circ}$ Regional de Saúde. A população do estudo foi de 192 mulheres, com a pesquisa realizada no período de 23 de Julho a 20 de Dezembro de 2017, utilizando um instrumento semiestruturado. Os dados foram reunidos no programa Microsoft Office Excel® 2013. A análise descritiva foi realizada com frequências absolutas e relativas. RESULTADOS: Após análise dos dados, observamos que $84,8 \%$ das gestantes realizaram o teste rápido para sífilis no primeiro trimestre de gestação, sendo que, $14,5 \%$ realizaram também o VDRL e 7,8\% o exame FTA-Abs. No segundo trimestre de gestação $70,3 \%$ das mulheres realizaram o teste rápido para sífilis, destas $14,0 \%$ realizaram o VDRL e 6,2\% o FTA-Abs. Já no terceiro trimestre de gestação 70,3\% das mulheres realizaram o teste rápido para sífilis, destas $11,9 \%$ fizeram o VDRL e 4,6\% 0 exame FTA-Abs. CONCLUSÃO: A assistência ao pré-natal ainda encontra-se falha, pois a totalidade das gestantes deveria ter realizado a testagem para Sífilis, com o objetivo de detecção precoce da doença, para realizar o tratamento e prevenir os efeitos da Sífilis congênita.

DESCRITORES: Sífilis Congênita; Exames Sorológicos; Saúde da Mulher.

\section{REFERÊNCIAS}

DOMINGUES, R. M. S. M.; LEAL, M. C. Incidência de sífilis congênita e fatores associados à transmissão vertical da sífilis: dados do estudo Nascer no Brasil. Caderno de Saúde Pública.v. 32,n. 6,e00082415,2016.

MAGALHÃES, D. M. S.; KAWAGUCHI, I. A. L.; DIAS, A.; CALDERON, I. M. P. A sífilis na gestação e sua influência na morbimortalidade materno infantil. Com Ciências Saúde. v. 22, supl. 1, S43-S54, 2011. 


\section{Obstétrica,2019;09-67}

Ministério da Saúde (BR). Secretaria de Atenção à Saúde. Área Técnica de Saúde da Mulher. Manual Técnico. Pré-natal e puerpério: atenção qualificada e humanizada. Brasília: DF, 2006.

PADOVANI, C.; OLIVEIRA, R. R.; PELLOSO, S. M. Syphilis in during pregnancy: association of maternal and perinatal characteristics in a region of southern Brazil. Revista Latino-Americana de Enfermagem. v. 26, e3019, 2018. 


\section{INDUÇÃO DO TRABALHO DE PARTO DE GESTANTES EM MATERNIDADES PÚBLICAS DE LONDRINA/PR}

Maria Caroline Rogerio*, Jéssica Maia Storer, Keli Regiane Tomeleri da Fonseca Pinto *Universidade Estadual de Londrina, Londrina/PR,
mcarolrogerio@hotmail.com

INTRODUÇÃO: O programa Rede Mãe Paranaense propõe a organização da atenção materno-infantil no período do pré-natal, puerpério e nos primeiros anos de vida do bebê, de forma a garantir uma experiência tranquila e com qualidade às mulheres. De acordo com a Organização Mundial da Saúde, violência obstétrica é qualquer atitude negligente, desrespeitosa, desumanizada e de maus tratos à parturiente e seu respectivo bebê que possa causar sofrimento físico ou psíquico. Desta forma, utilizar de práticas que acelerem o curso natural do parto, como medicações e manobras sem necessidade, tornou-se uma forma de violência obstétrica que vai contra os princípios e direitos das mulheres, reafirmados pelo programa Rede Mãe Paranaense. OBJETIVO: Medir a prevalência de indução do trabalho de parto em maternidades públicas do município de Londrina/Pr. MÉTODO: Trata-se de uma pesquisa quantitativa, recorte da pesquisa intitulada "Rede Mãe Paranaense na perspectiva da usuária: o cuidado da mulher no pré-natal, parto, puerpério e da criança", realizada nas maternidades dos municípios de médio porte da 17ª Regional de Saúde. Foi realizado entrevista com 299 mulheres, no período julho a dezembro de 2017, utilizando um instrumento semiestruturado. Os dados foram reunidos no programa Microsoft Office Excel® 2013. A análise descritiva foi realizada com frequências absolutas e relativas. Este estudo atendeu as questões éticas e legais, com parecer favorável no 2.053 .304 e CAEE: 67574517.1.1001.5231. RESULTADOS: Da população de estudo, 76,9\% eram de mulheres com gestação de baixo e risco intermediário e, apenas, $23,1 \%$ de alto risco. A prevalência de indução no trabalho de parto foi de $45,8 \%$, sendo que, em $76,6 \%$ a indução foi realizada com ocitocina e em $23,4 \%$ com misoprostol. CONCLUSÃO: Pode-se concluir que, que a indução do trabalho de parto ainda é uma prática rotineira presente nas maternidades, pois, considera-se a gestação como um processo fisiológico sem o uso de intervenções ou quando necessárias, com 0 embasamento de evidências científicas.

DESCRITORES: Maternidades; Obstetrícia; Saúde da Mulher; Trabalho de Parto.

\section{REFERÊNCIAS}

PARANÁ. Rede Mãe Paranaense. 2012 (citado em 2019 maio 20). Disponível em: saude.pr.gov.br/modules/conteudo/conteudo.php?conteudo=2892.

MOURA, R. C. M.; PEREIRA, T. F.; REBOUÇAS, F. J.; COSTA, C. M.; LERNADES, A. M. G.; SILVA, L. K. A.; ROCHA, K. M. M. Cuidados de enfermagem na prevenção da violência obstétrica. Enfermagem em foco. v.9, n. 4, p. 60-65, 2018. 


\section{UTILIZAÇÃO DE TERAPIAS NÃO FARMACOLÓGICAS EM MATERNIDADES DE PEQUENO PORTE NO NORTE DO PARANÁ}

Pamela Panas dos Santos Oliveira*, Kawany de Paula Lima, Maria Caroline Rogério, Luana da Silva, Keli Tomeleri da Fonseca Pinto

*Universidade Estadual de Londrina, Londrina-PR, e-mail: pamela panas@hotmail.com

INTRODUÇÃO: O parto é um evento natural que não necessita de controle, mas sim de cuidados, porém pode desencadear dor e desconforto por causa das contrações uterinas. Assim, cabe a equipe de saúde fornecer métodos de alívio e conforto. A Organização Mundial da Saúde, incentiva o uso de terapias não farmacológicas para alívio da dor e desconforto durante o trabalho de parto, como uso de massagem, banho de relaxamento, bola, musicoterapia, hidroterapia, entre outros. Atualmente, encontramos pesquisas com resultados positivos sobre 0 uso dessas terapias complementares. OBJETIVO: Identificar a prevalência do uso de terapias não farmacológicas em parturientes de três maternidades de pequeno porte na região norte do Paraná. MÉTODO: Trata-se de uma pesquisa quantitativa, recorte da pesquisa "Rede Mãe Paranaense na perspectiva da usuária: o cuidado da mulher no pré-natal, parto, puerpério e da criança", realizada em maternidades de pequeno porte da $17^{\circ}$ Regional de Saúde. Foi realizado entrevista com 192 mulheres, no período de 23 de julho de 2017 a 20 de dezembro de 2017, utilizando um instrumento semiestruturado. Os dados foram reunidos no programa Microsoft Office Excel® 2013. A análise descritiva foi realizada com frequências absolutas e relativas. RESULTADOS: Evidenciou-se que a maior parte das parturientes $(90,1 \%)$ recebeu pelo menos um tipo de terapia não farmacológica durante o trabalho de parto. Sendo que, $62,0 \%$ realizaram o banho de relaxamento, 22,4\% a bola, 22,4\% a massagem e $4,7 \%$ a musicoterapia. CONCLUSÃO: As maternidades estudadas estão buscando reduzir 0 desconforto e a dor gerada no trabalho de parto, proporcionando as gestantes conforto e segurança, durante essa experiência única e individual, que é o parto, levando a uma assistência humanizada.

DESCRITORES: Trabalho de Parto; Dor do Parto; Terapias Complementares.

\section{REFERÊNCIAS}

GALLO, R. B. S. et al. Recursos não farmacológicos no trabalho de parto: protocolo assistencial. Ministério da Saúde, São Paulo, p.1-8, jan. 2011.

MAFETONI, R. R.; SHIMO, A. K. K. Non-pharmacological methods for pain relief during labor: integrative review. Reme. v. 18, n. 2, p.1-8, 2014.

DAVIM, R.M.B., et al. Banho de chuveiro como estratégica não farmacológica no alívio da dor em parturientes. Revista Eletronica de Enfermagem. 2008.

LOPES, T.C.; MADEIRA, L.M.; COELHO, S. O uso da bola do nascimento na promoção da posição vertical em primíparas durante o trabalho de parto. Reme. 2003

LONDRINA, 2019. 


\section{O USO DE MÉTODOS ANTICONCEPCIONAIS E GRAVIDEZ NÃO PLANEJADA EM GESTANTES DE ALTO RISCO}

Márcia Aparecida dos Santos Silva Canario*, Francieli Ferreira de Andrade Batista, Natália Shinkai Binotto, Susany Franciely Pimenta, Talita Vidotte Costa, Rosangela Aparecida Pimenta Ferrari

*Universidade Estadual de Londrina, Londrina-Pr, e mail: marcia.s.s.canario@gmail.com

INTRODUÇÃO: A gravidez não planejada é considerada aquela que não foi programada pelo casal ou pela mulher, e pode trazer diversos agravos em relação ao cuidado com o recém-nascido, além de morbidades e mortalidades relacionada ao aborto. No cenário nacional, pode ser considerada um problema de saúde pública devido a falha no controle do processo reprodutivo. Além disso, a não utilização de métodos contraceptivos é a principal causa da gravidez não planejada nos países pouco desenvolvido. OBJETIVO: Estimar a frequência de gravidez não planejada e o uso de método contraceptivo em gestantes de alto risco. MÉTODO: Este estudo é parte de uma pesquisa multicêntrica financiada pelo Conselho Nacional de Desenvolvimento Científico e Tecnológico com o título "Rede Mãe Paranaense na Perspectiva da Usuária: o cuidado da mulher no pré-natal, parto, puerpério e da criança", envolvendo a Universidade Estadual de Londrina e a Universidade Estadual do Oeste do Paraná, campi de Cascavel e Foz do Iguaçu. Trata-se de um estudo transversal descritivo aninhado a uma coorte prospectiva, a análise desse estudo está restrita a maternidade referência para parto de alto risco na $17^{\circ}$ regional do Paraná, certificada pela Iniciativa Hospital Amigo da Criança que atende exclusivamente através do Sistema Único de Saúde, sendo a amostra final de 69 mulheres. A coleta de dados foi realizada no período de julho a dezembro de 2017, por meio de entrevista um dia após o parto, com aplicação de um formulário estruturado e para obtenção de dados sociodemográfico, características do pré-natal, parto e pós-parto imediato. Os dados foram analisados por meio do programa Statistical Package for Social Sciences, versão 20.0. Esta pesquisa seguiu as normas da resolução 466/12 do Conselho Nacional em Saúde e foi aprovada pelo Comitê de Ética em Pesquisa Envolvendo Seres Humanos da Universidade Estadual de Londrina, CAAE: 67574517.1.1001.5231. RESULTADOS: A gravidez não planejada foi mencionada por 44,9\% (31) dos casais, no entanto $44,9 \%$ (31) disseram não fazer uso de método contraceptivo e $29 \%$ (20) utilizavam contraceptivo oral, desses $17,4 \%$ (12) referiram o método como escolha própria. Entre os motivos para não utilizar contraceptivo 47,8\% (33) afirmaram o desejo de engravidar, apenas 4,3\% (3) apresentaram problemas com o anticoncepcional e a maioria 44,9\% (31) citaram o profissional de saúde como meio para obter informações a respeito do planejamento reprodutivo. CONCLUSÃO: Constatou-se que a gravidez não planejada ocorre principalmente pela falta de adesão de métodos contraceptivos, sendo necessário implementar e/ou redirecionar ações e estratégias para prevenção e diminuição, sendo imprescindível o envolvimento da equipe multiprofissional e instituições de saúde.

DESCRITORES: Anticoncepcionais; Gravidez de alto risco; Gravidez não-planejada. 


\section{REFERÊNCIAS}

BONNATTI, F. A. et tal. Fatores Associados ao Tipo de Gestação não Planejada na Estratégia de Saúde da Família. Revista de Pesquisa: Cuidado é Fundamental Online. v.10, p. 871-876, 2018. 


\section{PERFIL E TAXA DE INCIDÊNCIA DE GESTANTES COM SÍFILIS NO BRASIL NOS ÚLTIMOS DEZ ANOS}

Larissa Pereira Falavina*, Nathalia Jung Ferreira Malta, Giovanna Moreira de Pontes, Rosana Rosseto de Oliveira

*Universidade Estadual de Londrina, Londrina-PR, e-mail: falavinalarissa@gmail.com

INTRODUÇÃO: A sífilis é uma infecção sexualmente transmissível na maioria dos casos, causada pela bactéria Treponema Pallidum que apresenta várias manifestações clínicas e vários estágios de evolução. O estágio mais grave é quando ocorrem lesões ósseas, cardiovasculares e neurológicas até levar ao óbito. Quando acomete a gestante, pode ser transmitida ao feto/recém-nascido causando morte fetal, prematuridade e complicações após o nascimento. OBJETIVO: Identificar o perfil e a taxa de incidência de sífilis em gestante no Brasil, nos últimos dez anos. MÉTODO: Estudo do tipo ecológico e transversal dos casos de sífilis em gestantes no Brasil, notificadas no Sistema de Informação de Agravos de Notificação do Ministério da Saúde. O banco de dados é de acesso livre, disponível no site do Departamento de Informática do Sistema Único de Saúde. Para este estudo foi realizado download do banco de dados com as variáveis: número de casos de sífilis em gestantes notificados, escolaridade, faixa etária, classificação clínica da infecção, estado e município de residência da gestante. O período de estudo foi 2009 a 2018. Realizou-se estatística descritiva com frequências absolutas e relativas. Para o cálculo da taxa de incidência foi realizada a razão do número de casos de sífilis, pelo número de nascidos vivos (no mesmo local e período), com taxa multiplicativa de 10.000 , conforme preconizado pelo Ministério da Saúde. Os dados foram tabulados no Microsoft Excel 2007. RESULTADOS: A taxa de incidência de sífilis em gestante no Brasil foi de 110.65 casos por 10.000 nascidos vivos, no período de 2009 a 2018. A taxa aumentou ano a ano, passando de 18.27/10.000 em 2009 para 202.13/10.000 em 2018. O estado com maior número de casos foi São Paulo $(20,9 \%$; $n=60.750)$ seguido do Rio de Janeiro (14,9\%; $n=43.312)$, Minas Gerais (6,8\%; $n=19.678)$ e Rio Grande do Sul $(6,7 \% ; n=$ $19.557)$. Quanto ao perfil das gestantes, a maioria (20,2\%) tinha o ensino fundamental incompleto, $71,3 \%$ com faixa etária entre 20 e 39 anos, seguido das adolescentes $(25,2 \%)$ e a classificação clínica da infecção era primária $(31,2 \%)$. CONCLUSÃO: No Brasil, houve aumento da taxa de incidência de sífilis em gestante nos últimos dez anos. Apesar de haver diferenças no número de casos de acordo com o estado de residência, os dados são alarmantes de uma maneira geral, pois o aumento esteve presente em todas as regiões do país. Este estudo pode colaborar para que políticas públicas sejam reforçadas no sentido de bloquear a cadeia de transmissão, prevenção, manejo e tratamento adequado e oportuno da sífilis, diminuindo os riscos para a saúde da gestante e recém-nascido.

DESCRITORES: Gestação; Sífilis; Mortalidade Materna.

\section{REFERÊNCIAS}

World Health Organization. Who Guidelines for the treatment of Treponema pallidum (syphilis). Geneva, 2016. 


\section{PRINCIPAIS CAUSAS DE ÓBITOS MATERNOS EM UM ESTADO BRASILEIRO, NO PERÍODO DE 2012 A 2016}

Larissa Pereira Falavina*, Gabriela Souza Alves Fraron, Yasmin Duque Franco, Rosana Rosseto de Oliveira

*Universidade Estadual de Londrina, Londrina-PR, e-mail: falavinalarissa@gmail.com

INTRODUÇÃO: A mortalidade materna é um desafio mundial de saúde pública, apresentando ainda taxas inaceitavelmente altas. A Organização Mundial da Saúde encoraja a adoção de medidas para a diminuição dos óbitos maternos, que com prénatal e assistência de qualidade poderiam ser majoritariamente evitados. OBJETIVO: Caracterizar as principais causas de óbitos maternos no estado do Paraná, no período de 2012 a 2016. MÉTODO: Estudo transversal, realizado no estado do Paraná com dados sobre as causas de óbitos maternos ocorridos no período de 2012 a 2016. Os dados foram obtidos no site do Departamento de Informática do Sistema Único de Saúde - DATASUS, do Ministério da Saúde, que disponibiliza as informações da declaração de óbito preenchida para cada óbito materno ocorrido. O banco de dados sobre mortalidade, disponibilizado pelo DATASUS é público e pode ser acessado por qualquer cidadão. As variáveis analisadas foram: causa do óbito de acordo com categorias da Classificação Internacional de Doenças em sua 10 â revisão (CID-10), tipo de causa (direta ou indireta), período do óbito (puerpério ou durante gravidez e parto), faixa etária, raça/cor, escolaridade e estado civil da gestante. Foi realizado download do banco de dados, e por meio do Microsoft Excel foi realizada estatística descritiva com frequências absolutas e relativas para caracterização dos óbitos. RESULTADOS: No estado do Paraná ocorreram 346 óbitos maternos, no período de 2012 a 2016. As principais causas de óbito, de acordo com a CID-10, foram: hemorragia pós-parto $(9,5 \% ; n=33)$, hipertensão gestacional com proteinúria $(7,2 \%$; $n=25)$, infecção puerperal $(6,1 \% ; n=21)$, eclâmpsia $(5,8 \% ; n=20)$, embolia na gestação $(5,5 \% ; n=19)$ e infecção do trato urinário na gestação $(4,9 \% ; n=17)$. As causas diretas foram maioria $(65,6 \%)$ e os óbitos aconteceram majoritariamente $(71,1 \%)$ no período puerperal (até 42 dias após o parto). Quanto ao perfil das gestantes que foram a óbito, a maioria tinha entre $30-39$ anos $(41,3 \%)$, era de raça/cor branca $(73,7 \%)$, tinha de oito a 11 anos de estudo (42,5\%) e era solteira (40,5\%). CONCLUSÃO: Este estudo mostrou as principais causas de mortalidade materna no estado do Paraná, entre 2012 e 2016, sendo as principais a hemorragia pós-parto, hipertensão gestacional, infecção puerperal, eclâmpsia, embolia e infecção urinária, todas passíveis de prevenção ou diagnóstico precoce com tratamento adequado. A assistência à gestação pode melhorar e ser direcionada para prevenção de complicações como as mostradas neste estudo, resultando em diminuição de óbitos na gestação. Neste cenário, os profissionais da saúde têm papel importante, principalmente o enfermeiro que atua na linha de frente no cuidado à gestante, seja na atenção primária, secundária ou terciária, e oportunidades de manejo adequado a complicações que levam ao óbito não podem ser perdidas.

DESCRITORES: Mortalidade Materna; Enfermagem Obstétrica; Gestação.

\section{REFERÊNCIAS}

WHO. Fact sheet: Maternal mortality. Geneva, 2018. Disponível em: https://www.who.int/news-room/fact-sheets/detail/maternal-mortality. Acesso em: 05 jun 2019. 


\section{MÉTODOS TERAPÊUTICOS UTILIZADOS EM TRAUMAS MAMILARES DE PUÉRPERAS EM UMA MATERNIDADE DE ALTO RISCO}

Luana da Silva*, Maria Caroline Rogerio, Pamela Panas dos S. Oliveira Kawany Lima, Keli Regiane Tomeleri da Fonseca Pinto

*Universidade Estadual de Londrina, Londrina/PR, e-mail: luanasilvaponciano@hotmail.com

INTRODUÇÃO: O trauma mamilar frequentemente se faz presente no período pósparto de diversas puérperas. Ele compreende uma ruptura do tecido epitelial do mamilo e/ou aréola, podendo se apresentar na forma de escoriação, fissura, vesícula, erosão ou até dilaceração. Esse evento gera desconforto e desmotivação frente ao aleitamento materno, no qual requer atenção por parte da equipe de saúde. OBJETIVO: Identificar a incidência de fissuras mamilares e os métodos terapêuticos utilizados para o tratamento em uma maternidade de um Hospital Universitário de Londrina. MÉTODO: Trata-se de um recorte da pesquisa intitulada "Rede Mãe Paranaense na perspectiva da usuária: o cuidado da mulher no pré-natal, parto, puerpério e da criança", cadastrada na PROPPG n. 10735 e aprovada na Chamada Universal MCTI/CNPq no 01/2016, realizada nas maternidades dos municípios de médio porte da 17a Regional de Saúde, no período de julho a dezembro de 2017. Neste trabalho, foram utilizados os dados obtidos na maternidade do Hospital Universitário de Londrina, com a população de 69 puérperas. RESULTADOS: Observou-se que $33,3 \%$ das mulheres apresentaram fissuras mamilares no pós-parto imediato. A partir disto, os principais métodos terapêuticos recomendados pela equipe às puérperas foram: $56,6 \%$ das puérperas relataram terem sido orientadas quanto ao uso de óleo e o próprio leite materno, $13 \%$ foram orientadas quanto ao uso de pomadas, $8,7 \%$ quanto a outras condutas, como o uso de sutiã e pega correta, entretanto, $17,4 \%$ relataram não terem recebido nenhuma orientação quanto ao tratamento das fissuras mamilares. CONCLUSÃO: A ocorrência de fissuras mamilares foi considerável nas puérperas, e que apesar de mais da metade ter recebido orientações sobre métodos terapêuticos para alívio da dor e melhora das fissuras, ainda há mulheres que não recebem informações e se tornam susceptíveis ao agravo das lesões, que consequentemente, poderá levara a uma possível interrupção do processo de amamentação.

DESCRITORES: Saúde da Mulher; Período Pós-Parto; Ferimentos e lesões.

\section{REFERÊNCIAS}

URASAKI, M. B. M. et al. Trauma Mamilar: Cuidados Adotados por Mulheres no Pósparto. Estima, v. 15, n. 1, p.26-34, 2017.

BARBOSA, D. M. et al. Assessment of factors associated to nipple trauma / Avaliação dos fatores associados ao trauma mamilar. Revista de Pesquisa: Cuidado é Fundamental Online,. v. 10, n. 4, p.1063-1069, 2018. 


\title{
10. PERFIL DE ATIVIDADE FÍSICA DE MULHERES GESTANTES DO HOSPITAL DAS CLÍNICAS
}

\author{
Mayara Aline Alexandrino dos Santos*, Patricia Chimin, Crivaldo Gomes Cardoso \\ Junior \\ *Universidade Estadual de Londrina, Londrina- PR, e mail: \\ mayaraline 21@hotmail.com
}

INTRODUÇÃO: A gestação é um marco importante e positivo para a maioria das mulheres, no entanto causa alterações posturais, fisiológicas, psicológicas e sociais. Já existem evidências de que a prática de atividade física regular durante a gravidez tem se mostrado eficaz para melhorar ou manter a aptidão física, ajudar no controle do peso, reduzir o risco de diabetes gestacional em mulheres obesas e aumentar o bemestar psicológico. Entretanto, apesar da prática de atividade física apresentar riscos mínimos e ter se mostrado benéfica para a maioria das mulheres, sendo recomendada no mínimo 150 minutos por semana em intensidade moderada, a adesão durante o processo gestacional ainda é difícil, pois as mulheres têm receios e dúvidas quanto a prática, além de relatarem cansaço e falta de tempo como outros impedimentos. OBJETIVO: Descrever o perfil do nível de atividade física de gestantes no $2^{\circ}$ trimestre gestacional atendidas pelo Hospital das Clínicas da Universidade Estadual de Londrina. MÉTODO: Trata-se de um estudo descritivo, cuja amostra foi composta por mulheres gestantes em acompanhamento pré-natal no setor 4 do Hospital das Clínicas da Universidade Estadual de Londrina. Os dados foram coletados a partir do Questionário de Atividade Física para Gestantes (QAFG), o qual consiste em 31 questões, divididas em 5 domínios, a saber: tarefas domésticas, cuidar de outras pessoas, ocupação, esportes/exercício, locomoção e lazer. Para avaliação dos níveis de atividade física foi utilizada a análise de frequências relativas, considerando a intensidade de cada atividade: sedentária (< 1,5 METs), leve (1,5 - < 3,0 METs), moderada (3,0 - 6,0 METs) ou vigorosa (> 6,0 METs). RESULTADOS: Das gestantes entrevistadas, ao analisarmos o nível de atividade física geral, 55\% praticavam atividade física em intensidade leve e somente 5\% apresentavam atividade física vigorosa. Além disso, o domínio com maior prevalência de atividade física foi a de "tarefas domésticas", com 60\% das gestantes apresentando atividades com classificação "moderada". Para os outros domínios, a maior parte das gestantes apresentaram nível de atividade física baixo, sendo classificadas como "sedentárias". CONCLUSÃO: Há uma prevalência de pouca atividade física durante o $2^{\circ}$ trimestre gestacional de mulheres atendidas pelo setor 4 do Hospital das Clínicas da Universidade Estadual de Londrina. Assim, sugerimos que trabalhos futuros investiguem as possíveis barreiras para a prática de atividade física nessa população a fim de promover políticas de incentivo à prática tanto durante quanto após o período de gestação.

DESCRITORES: Gestação; Atividade Física; Esforço Físico.

\section{REFERÊNCIAS}

ACOG. Physical activity and exercise during pregnancy and postpartum period. Commite Opinion, n. 650, p. 1-8, dez. 2015. 


\section{Obstétrica,2019;09-67}

CAMACHO, K. G.; VARGENS, O. M. C.; PROGIANTI, J. M.; SPÍNDOLA, T. Vivenciando repercussões e transformações de uma gestação: perspectivas de gestantes. Ciencia y Enfermaria, v.16, n.2, p.115-125, ago. 2010.

GOMES, D. O.; COSTA, G. M. T. Exercício físico na gravidez. Revista de Educação do Ideau, v.8, n.18, p. 1-12, jul./dez., 2013.

MANN, J.; KLEINPAUL, J. F.; TEIXEIRA, C. S.; MORO, A. R. P. Gravidez: Um estado de saúde, de mudanças e adaptações. Disponível em: <http://www.efdeportes.com/efd139/gravidez-um-estado-de-saude.htm>. Acesso em: 10 maio 2018.

RIBEIRO, C. P.; MILANEZ, H.; Knowledge, attitude and practice of women in Campinas, São Paulo, Brazil with respect to physical exercise in pregnancy: a descriptive study. Reproductive Health, v.8, n.31, p. 1-7, 2011.

SILVA, F. T. Avaliação do nível de atividade física durante a gestação. 2007. Dissertação (Mestrado em Saúde Pública) - Universidade Estadual do Ceará, Fortaleza, CE.

SILVA, L. J.; SILVA, L. R. Mudanças na vida e no corpo: vivências diante da gravidez na perspectiva afetiva dos pais. Escola Anna Nery Revista de Enfermagem, v.2, n.13, p.393-401, abr./jun., 2009. 


\title{
11. EFEITOS DO TREINAMENTO RESISTIDO SOBRE A FORÇA MUSCULAR, COMPOSIÇÃO CORPORAL E INDICADORES CARDIOMETABOLICOS DE MULHERES
}

\author{
Edilaine Fungari Cavalcante*, Yann Ferreira Rodrigues de Souza, Mayara Aline \\ Alexandrino dos Santos, Marcia Gabrielly Fantin Carvalho, Crivaldo Gomes Cardoso \\ Junior, Crisieli Maria Tomeleri
}

*Universidade Estadual de Londrina, Londrina-PR, e mail: edilainefungari@gmail.com

INTRODUÇÃO: O climatério é um período na vida da mulher que acontece várias alterações hormonais e está associado com modificações deletérias na força muscular, composição corporal e indicadores cardiometábolicos. Por outro lado, a prática regular de treinamento resistido pode atenuar ou até mesmo reverter as modificações deste processo. OBJETIVO: Analisar os efeitos de 12 semanas de treinamento resistido sobre a força muscular, composição corporal e indicadores cardiometábolicos de mulheres atendidas no Ambulatório Multiprofissional de Atenção à Saúde da Mulher. MÉTODO: A Residência Multiprofissional em Saúde da Mulher atua no Ambulatório de Especialidades do Hospital Universitário de Londrina-PR, onde está o Ambulatório Multiprofissional de Atenção à Saúde da Mulher que oferece diversos serviços, entre os serviços está a Academia Saúde da Mulher. Este estudo apresenta uma parte do trabalho realizado. Doze mulheres $\left(55,4 \pm 11,4\right.$ anos; $\left.31,96 \pm 7,07 \mathrm{~kg} / \mathrm{m}^{2}\right)$ fisicamente independentes foram selecionadas para participar deste estudo. As participantes deveriam ser atendidas pelo Ambulatório de Especialidades, encaminhadas para 0 Ambulatório Multiprofissional de Atenção à Saúde da Mulher e depois de realizarem uma triagem de risco para prática de atividade e apresentar disponibilidade, foram convidadas para participar da Academia Saúde da Mulher. O programa de exercícios resistidos teve a duração de 12 semanas, realizado em dias alternados (segunda, quarta e sexta) três vezes por semana no período da manhã. As sessões de treinamento foram divididas em três partes: (1) aquecimento geral = caminhada (10 minutos); (2) parte principal = programa com exercícios resistidos para o corpo todo (10 exercícios $=40$ minutos, três séries de 10-15 repetições máximas), (3) volta a calma $=$ alongamento (10 minutos). As avaliações foram realizadas antes e após a intervenção. A força muscular foi estimada a partir do teste de uma repetição máxima (1-RM), onde foi realizado dois exercícios, cadeira extensora e rosca scott, representando membros inferiores e membros superiores, respectivamente; a composição corporal foi avaliada a partir da bioimpedância elétrica (BIA/ Vitality Analyzer) e a coleta sanguínea foi utilizada para analisar os indicadores cardiometábolicos. Os resultados são apresentados em média e desvio padrão ou em delta percentual, para análise estatística foi utilizado teste t de student e foi adotado o nível de significância de $5 \%$. RESULTADOS: Efeito do tempo foi observado $(P<0,05)$ no qual o grupo de intervenção aumentou a força muscular (cadeira extensora $=+24,0 \%$; rosca scott $=+$ $6,6 \%$ ), melhorou a composição corporal (massa magra $=+0,5 \%$; massa gorda $=-0,6$ $\%$ ) e indicadores cardiometabólicos (glicose em jejum $=-4,2 \%$; colesterol total $=-4,9$ $\% ; \mathrm{HDL}=+2,8 \%$; LDL $=-7,2 \%$ e triglicerídeos $=-4,5 \%$ ). CONCLUSÃO: Os resultados sugerem que o treinamento resistido traz melhorias nos indicadores de saúde de mulheres. 


\section{Obstétrica,2019;09-67}

DESCRITORES: Atividade Física; Mudança de Vida; Mulheres.

\section{REFERÊNCIA}

Brasil. Ministério da Saúde. Secretaria de Atenção à Saúde. Departamento de Ações Programáticas Estratégicas. Manual de Atenção à Mulher no Climatério/Menopausa / Ministério da Saúde, Secretaria de Atenção à Saúde, Departamento de Ações Programáticas Estratégicas. - Brasília: Editora do Ministério da Saúde, 2008. 


\section{ANALISE DA ASSISTENCIA PRÉ-NATAL EM UM MUNICIPIO COM IMPLEMENTAÇÃO DA REDE MÃE PARANAENSE}

Jennifer Stefany de Mello Vicente*, Demely Biason Ferreira, Catia Campaner Ferrari Bernardy, Ana Carolina Sousa, Thelma Malagutti Sodré, Keli Regiane Tomeleri da Fonseca Pinto

*Universidade Estadual de Londrina, Londrina-PR, e mail: jennifer uni@outlook.com

INTRODUÇÃO: O pré-natal tem o objetivo de proporcionar uma gestação e parto seguros, com a captação precoce da gestante, afim de, prevenir agravos maternos e neonatais e promover a saúde de ambos. Neste momento, é possível também que os profissionais de saúde provoquem na mulher a reflexão a respeito do processo de gestação e parto, para que desta forma, ela possa fazer parte deste processo. Em 2012 foi implantado a Rede Mãe Paranaense com o objetivo de reduzir a mortalidade materno infantil no estado, a partir do acompanhamento do pré-natal, com no mínimo 7 consultas e 1 consulta no puerpério, realização de no mínimo 18 exames e classificação de risco, já que ainda há um número expressivo de mortes desta categoria na realidade social e sanitária do Brasil. OBJETIVO: Analisar a assistência pré-natal de mulheres atendidas em uma maternidade referência para risco habitual com implementação da Rede Mãe Paranaense. MÉTODO: Este estudo faz parte da pesquisa multicêntrica intitulada: "Rede Mãe Paranaense na Perspectiva da Usuária: $O$ cuidado da Mulher no Pré-Natal, Parto, Puerpério e da Criança”. Trata-se de um estudo quantitativo, desenvolvido com puérperas entre junho e novembro de 2017 que pariram na maternidade do Hospital São Rafael do município de Rolândia-PR. Este serviço é referência para 6 municípios de pequeno porte. A coleta foi por meio de entrevista direta, análise de prontuário e cartão da gestante. A pesquisa foi aprovada pelo Comitê de Ética da Universidade Estadual de Londrina sob parecer 67574517.1.1001.5231. RESULTADOS Foram analisadas 59 gestantes, sendo que $74 \%$ delas tinham idade entre 20-34 anos. Observou-se que 54\% eram de raça branca, 57\% não tinham companheiro e $94,9 \%$ estudaram 8 anos ou mais, o que impacta em menor risco de mortalidade infantil, porém $81 \%$ das gestantes são do lar ou exercem funções não remuneradas, mesmo com melhor grau de escolaridade. Grande parte das gestantes $(84,7 \%)$ realizou o pré-natal em sua Unidade Básica de Saúde de referência e foram classificadas $(71,1 \%)$ quanto ao risco gestacional habitual, no entanto, $18,6 \%$ delas foram classificadas como risco intermediário e $8,4 \%$ de alto risco. Possivelmente este fato ocorreu por alguma falha no sistema de encaminhamento. Conforme preconizado, o pré-natal iniciou-se o mais precocemente possível (até o final do 3ํㅡês de gestação) em $83,05 \%$ das gestantes, o que garantiu que $74,5 \%$ realizasse 6 ou mais consultas durante a gravidez. Quanto a qualidade do pré-natal segundo Coutinho, somente $18,6 \%$ gestantes tiveram seus pré-natais considerados inadequados, sendo que a maioria $81,3 \%$ foi classificada como adequado ou intermediário. CONCLUSÃO: A análise dos dados reforça a importância das ações implementadas pela Rede Mãe Paranaense, já que refletem diretamente na melhoria da assistência prestada a mãe e ao bebê. Por isso, as constantes melhorias na qualidade da assistência pré-natal, impactam consideravelmente na redução da morbimortalidade materno-infantil, pois permite a identificação precoce de problemas, constante reavaliação de risco e imediata conduta.

DESCRITORES: Cuidado pré-natal; Gestantes; Gravidez. 


\section{Obstétrica,2019;09-67}

\section{REFERENCIAS}

COUTINHO, T. et al. Monitoramento do processo de assistência pré-natal entre as usuárias do Sistema Único de Saúde em município do Sudeste brasileiro. Revista Brasileira de Ginecologia e Obstetricia. v. 32, n. 11, p. 563-569, 2010.

LONDRINA. Secretaria Municipal de Saúde. Manual do cuidado no pré-natal e puerpério na atenção primária em Saúde. 2a edição, 2016. Disponível em:< http://www1.londrina.pr.gov.br/dados/images/stories/Storage/sec_saude/protocolos_clin icos_saude/manual_cuidado_pre-natal_puerperio_atencao_primaria_saude.pdf $>$. Acesso em: 22 de maio de 2019.

BRASIL. Ministério da saúde. Manual prático para a implementação da Rede Cegonha. Brasília: [s.n.], 2011. Disponível em: <www.saude.mt.gov.br/arquivo/3062>. Acesso em: 23 jun. 2019.

PARANÁ. Linha Guia Rede Mãe Paranaense. Secretaria de Estado da Saúde do Paraná.

$<$ http://www.saude.pr.gov.br/arquivos/File/ACS/linha_guia_versao_final.pdf>. Acesso em: 22 de maio de 2019. 


\section{SATISFAÇÃO DA PUÉRPERA COM A ASSISTÊNCIA EM UMA MATERNIDADE DE ALTO RISCO}

Maria Caroline Rogerio*, Luana da Silva, Pamela Panas dos S. de Oliveira, Kawany de Paula Lima, Keli Regiane Tomeleri da Fonseca Pinto

*Universidade Estadual de Londrina, Londrina/PR, E mail:
mcarolrogerio@hotmail.com

INTRODUÇÃO: O período do parto e puerpério é marcado por diversas mudanças, principalmente fisiológicas e psíquicas, além de ser necessário adaptações e a reestruturação do ambiente familiar no qual o bebê será inserido. O cuidado da equipe de saúde com a mulher neste momento é imprescindível e se configura como uma rede de apoio que fornece educação em saúde, orientações quanto ao autocuidado e cuidado com o bebê, amamentação, formas de alívio da dor durante o momento do parto e diversas outras informações. Portanto, neste momento vulnerável da mulher é de extrema importância uma equipe que forneça confiança, respeito e a faça se sentir confortável e segura. OBJETIVO: Verificar a satisfação das puérperas com a assistência recebida durante o parto em uma maternidade de alto risco. MÉTODO: Trata-se de uma pesquisa quantitativa, recorte da pesquisa intitulada "Rede Mãe Paranaense na perspectiva da usuária: o cuidado da mulher no pré-natal, parto, puerpério e da criança", realizada nas maternidades dos municípios de médio porte da 17ª Regional de Saúde. O cenário de estudo foi uma maternidade de alto risco. A população foi composta por 69 puérperas. As entrevistas foram realizadas entre julho a dezembro de 2017, utilizando um instrumento semiestruturado. Os dados foram reunidos no programa Microsoft Office Exce|® 2013. A análise descritiva foi realizada com frequências absolutas e relativas. Este estudo atendeu as questões éticas e legais, com parecer favorável no 2.053.304 e CAEE: 67574517.1.1001.5231. RESULTADOS: As puérperas $(91,3 \%)$ demonstraram estar satisfeitas com a assistência recebida, sendo que, $98,6 \%$ e $97,1 \%$, respectivamente, não se sentiram desrespeitadas no momento do parto e nem ofendidas. 36,2\% das puérperas consideraram que havia muitas pessoas presentes no parto, o que é considerado falta de privacidade. CONCLUSÃO: As puérperas mostraram-se satisfeitas com o atendimento recebido, embora algumas consideraram o número de pessoas no momento do parto excessivo. Embora o local do estudo seja um hospital escola, deve haver mais cautela, e realmente participar desse momento somente as pessoas necessárias, pois se trata de um momento sublime e único para a mulher e a presença de atores estranhos e em excesso tira a privacidade da mulher, o que pode leva-la a não vivenciar o parto da melhor maneira possível.

DESCRITORES: Maternidades; Gestação de alto risco; Saúde da Mulher.

\section{REFERÊNCIAS:}

XAVIER, A. C. A.; JESUS, M. G. R.; PEREIRA, A. S.; SANTOS, K. A.; FERREIRA, D. A. S.; SALES, S. N. V. Cuidados com o recém-nascido. Rede FTC. v. 1, n. 1, p.168$172,2015$.

SILVA, R. M.; SOUSA, A. K. A.; ABREU, R. M. S. X.; SILVA, R. A.; FARIAS, M. C. A. D. Atuação da enfermagem em alojamento conjunto: percepção de puérperas. Revista Brasileira de Educação e Saúde. V.5, n. 3, p 8-17, 2015. 


\section{RASTREAMENTO DO CONSUMO DE ÁLCOOL DURANTE O PRÉ-NATAL REALIZADO NA ATENÇÃO BÁSICA}

Rubia Mariana de Souza Santos*, Aroldo Gavioli, Sonia Silva Marcon, Patricia Chatalov Ferreira

*Programa de Pós-graduação em enfermagem PSE/UEM, Maringá-PR, e mail: rubia mariana@hotmail.com

INTRODUÇÃO: A base de evidências para rastreio do consumo de bebidas alcoólicas na gestação é ainda escassa. Sabe-se que algumas mulheres usam bebidas alcoólicas, necessitando de apoio e tratamento específicos. Em estudo realizado em um município no noroeste do Paraná observou-se consumo de bebidas alcoólicas em $27,2 \%$ das gestantes rastreadas. O teste Tolerance, Annoyed, Cut Down and Eyeopener (T-ACE) é específico para triagem do consumo de BA por gestantes, apontando a tolerância ao álcool, o aborrecimento com relação ao modo de beber, a percepção da necessidade de redução do consumo e o forte desejo e compulsão para beber durante a manhã. A identificação e o gerenciamento do consumo de bebidas alcoólicas na gestação deve ser componente essencial para otimizar a saúde e o bemestar das mulheres e seus filhos. OBJETIVOS: Avaliar o consumo de bebidas alcoólicas por gestantes de um municipio do noroeste do Paraná com o uso do Instrumento de rastreamento T-ACE. MÉTODOS: Estudo transversal, realizado com 179 gestantes que realizavam pré-natal na rede de atenção básica que responderam a roteiro de entrevista composto de questionário de variáveis sociodemográficas e gestacionais e do instrumento de rastreamento do consumo de BA T-ACE. Projeto submetido ao Comitê de Ética Uningá, sendo aprovado de acordo com parecer ํㅡ. 2.514.645. RESULTADOS: Observou-se idade média de 26,1 anos (DP \pm 5,95 anos), brancas $(67,6 \%)$, Católicas $(51,4 \%)$, casadas $(82,7 \%)$, com ensino médio completo $(39,7 \%)$, donas de casa $(43,6 \%)$, com renda familiar média de $R \$ 2247,52$ (DP \pm 996,11 Reais) e que conviviam com pai $(16,8 \%)$ ou parceiros $(17,8 \%)$ usuários de bebidas alcoólicas. Com relação ao consumo de bebidas alcoólicas, triado com o TACE, verificou-se que $40,2 \%$ das mulheres necessitavam de mais que duas doses padrão de bebidas alcoólicas para se sentirem altas; $20,1 \%$ já se aborreceram por ser criticadas pelo modo de beber; $25,7 \%$ já haviam tentado parar de beber e 8,4\% referiram utilizar BA logo pela manhã para "firmar o pulso". Os achados indicam que estas gestantes apresentam uso sustentado de bebidas alcoólicas acima do verificado em outros estudos, que mostram o consumo de algum tipo de droga de abuso por $18,28 \%$ na região de Maringá, PR, e 27,2\% de gestantes usuárias de bebidas alcoólicas em município do noroeste do Paraná. A abordagem sobre o uso de bebidas alcoólicas de maneira detalhada e abrangente permite aumentar a conscientização da mulher sobre os riscos associados ao consumo, funcionando na modificação de seu comportamento sendo fortemente recomendado pela Organização Mundial de Saúde, uma vez que a prevenção reduz e, até mesmo, interrompe o uso de da durante a gravidez. CONCLUSÃO: As gestantes eram em sua maioria jovens, brancas, católicas, casadas, com renda familiar menor que 3 salários mínimo e que conviviam com familiar ou companheiro que eram usuários de bebidas alcoólicas. O número de mulheres que apresentam consumo sustentado de bebidas alcoólicas triado pelo Instrumento T-ACE foi elevado na amostra em tela, quando comparado a outros estudos.

DESCRITORES: Programas de Rastreamento; Gravidez; Saúde da Mulher. 


\section{Obstétrica,2019;09-67}

\section{REFERÊNCIAS}

KASSADA, D.S. et al. Prevalência do uso de drogas de abuso por gestantes. Acta Paulista de Enfermagem. v. 26, p.467-471, 2013.

SANTOS, R.M.S; GAVIOLI, A. Risk related to abuse of drugs in pregnant women. . v 18, n.1, p. 35-42, 2017.

SMITH, L. et al. Alcohol comsumption during pregnancy: cross-sectional survey. Midwifery. v. 30, n.12, p. 1173-8, 2014.

SOKOL, R. J.: MARTIER, S.S.; AGER, J. W. The T-ACE questions: Practical prenatal detection of risk-drinking. American Journal of Obstetrics and Gynecology, v. 160, n.4, p. 863-870, 1989.

WHO. Guidelines for identification and management of substance use and substance use desorders in pregnancy. Geneza- Switzerlannd: World Healt Organization, 2014. 


\section{A VIVÊNCIA DO PARTO NORMAL: PERCEPÇÃO E SATISFAÇÃO DAS PUERPERAS}

Ana Letícia Moreira Parizi ${ }^{*}$, Janaina Silva de Oliveira Assunção, Andre Estevam Jaques

*Universidade Estadual de Maringá, Maringá-PR, e mail: analmparizi@hotmail.com

INTRODUÇÃO: $\mathrm{Na}$ antiguidade as mulheres eram preparadas para parir de maneira natural e a assistência à mulher era exclusivamente feminina, através das parteiras. No século XIX iniciou-se uma campanha contra a atuação das parteiras e no século XX consolidou-se a hospitalização do parto, passando a ser considerado como um evento patológico somado a adoção da posição litotômica no momento de parir. Essa nova maneira de enxergar o nascimento foi justificada pela busca da assistência que garantisse aparente segurança para mãe e bebê, porém, favoreceu a comodidade da equipe e a submissão e falta de autonomia da mulher. Com o perpassar do tempo, é notório que o parto é vivenciado, por muitas mulheres, como um momento de angústia e sofrimento, o que dificulta a evolução do processo fisiológico. A Organização Mundial da Saúde defende que é necessário adotar um conjunto de condutas que respeite o processo natural do parto, evitando condutas desnecessárias ou de risco, voltando a atenção da equipe para a mulher e suas individualidades. OBJETIVO: Analisar os fatores associados à satisfação das mulheres com a assistência ao parto normal. MÉTODO: Estudo exploratório, de abordagem qualitativa, realizado com 7 mulheres que tiveram parto normal em uma instituição privada, especializada no acompanhamento da gestação, parto e puerpério em um município do noroeste do Paraná. Foi abordada a questão: Fale-me qual foi sua percepção em relação à assistência ao parto normal. Utilizou-se conceitos de uma ferramenta gerencial, a Matriz SWOT para análise dos dados. RESULTADOS: Foram categorizadas potencialidades e limitações percebidas na assistência, dentre elas: a importância do vínculo com a equipe, a presença de um acompanhante de sua escolha, vínculo mãebebê imediato, experiência de autoconhecimento e empoderamento, rápida recuperação após o parto; falta de estrutura adequada e desvalorização do parto; facilidade no acesso às informações disponíveis e respeito por parte da equipe; condições impostas pela equipe médica e possibilidade de passar por violência obstétrica. CONCLUSÃO: As experiências negativas ou positivas pela qual a mulher passa durante 0 trabalho de parto e parto influenciam diretamente na percepção da experiência pela mesma, marcando a mulher de forma inexorável, podendo interferir na evolução do puerpério. Há ainda a necessidade de um maior número de estudos relacionados a essa temática, para que os profissionais sejam conscientizados sobre o assunto e sua importância, a fim de promover o incentivo e apoio ao parto normal, respeitando seus aspectos fisiológicos.

DESCRITORES: Enfermagem Obstétrica; Parto Normal; Parto Humanizado.

\section{REFERÊNCIAS}

Carraro, Telma Elisa, et al. O papel da equipe de saúde no cuidado e conforto no trabalho de parto e parto: opinião de puérperas. Texto \& Contexto Enfermagem 17.3 (2008): $\quad 502-509 . \quad$ Disponível em: shttps://www.redalyc.org/pdf/714/71417313.pdf?; 
Obstétrica,2019;09-67

CRIZÓSTOMO, Cilene Delgado; NERY, Inez Sampaio; LUZ, Maria Helena Barros. A vivência de mulheres no parto domiciliar e hospitalar. Escola Anna Nery Revista de Enfermagem, v. 11, n. 1, p. 98-104, 2007. Disponível em: < https://www.redalyc.org/pdf/1277/127715305014.pdf>;

MEDEIROS, Renata Marien Knupp; DOS SANTOS, Inês Maria Meneses; DA SILVA, Leila Rangel. A escolha pelo parto domiciliar: história de vida de mulheres que vivenciaram esta experiência. Escola Anna Nery Revista de Enfermagem, v. 12, n. 4, p. 765-772, 2008. Disponível em: <https://www.redalyc.org/pdf/1277/127715323022.pdf>;

MELCHIORI, Lígia Ebner et al. Preferência de gestantes pelo parto normal ou cesariano. Interação em psicologia, v. 13, n. 1, 2009. Disponível em: < https://revistas.ufpr.br/psicologia/article/view/9858>;

PIRES, Fernanda Maria de Jesus S. et al. A humanização e a assistência de enfermagem ao parto normal. Revista Brasileira de Enfermagem, v. 60, n. 4, p. 452455, 2007. Disponível em: < https://www.redalyc.org/pdf/2670/267020026014.pdf>;

DO CARMO OLIVEIRA, Daniela et al. Estrutura organizacional da atenção pós-parto na Estratégia Saúde da Família. Escola Anna Nery Revista de Enfermagem, v. 17, n. 3, p. 446-454, 2013. Disponível em: $<$ https://www.redalyc.org/pdf/1277/127728368007.pdf>;

DE FIGUEIREDO PEREIRA, Adriana Lenho; BENTO, Amanda Domingos. Autonomia no parto normal na perspectiva das mulheres atendidas na casa de parto. Revista da Rede de Enfermagem do Nordeste, v. 12, n. 3, p. 471-477, 2011. Disponível em: < https://www.redalyc.org/pdf/3240/324027976004.pdf>;

SANTOS, Isaqueline Sena; OKAZAKI, E. L. F. J. Assistência de enfermagem ao parto humanizado. Rev Enferm UNISA, v. 13, n. 1, p. 64-8, 2012. Disponível em: <https://s3.amazonaws.com/academia.edu.documents/49348340/Assistencia de enfer magem ao parto.pdf?response-content-

disposition=inline \%3B\%20filename\%3DAssistencia de enfermagem ao parto human .pdf\&X-Amz-Algorithm=AWS4-HMAC-SHA256\&X-Amz-

Credential=AKIAIWOWYYGZ2Y53UL3A\%2F20190816\%2Fus-east-

1\%2Fs3\%2Faws4 request\&X-Amz-Date=20190816T114745Z\&X-Amz-

Expires $=3600 \& X-A m z-S i g n e d H e a d e r s=h o s t \& X-A m z-$

Signature $=44946789 e e 989 f 037 d d c 6 b 2 b 14 b 49 e 3868 b e 86 f d 0 d 574 f a b c e 23 b 230981849$

$\underline{1 \mathrm{c}}>$;

SANTOS, Gilmara S. et al. A importância do enfermeiro no atendimento humanizado no pré-parto. Diálogos Ciênc, v. 10, n. 31, p. 224-8, Faculdade de Tecnologia e Ciência (FTC) Salvador, BA, Brazil. 2012. doi: 10.7447/dc.2012.025. Disponível em: $<$ http://dialogos.ftc.br>;

Souza LPS, Souza AMV, Pereira KG, Figueiredo T, Bretas TCS, Mendes MAF, et al. Matriz SWOT como ferramenta de gestão para melhoria da assistência de enfermagem: estudo de caso em um hospital de ensino. Revista Eletrônica Gestão \& Saúde. 2013; 4(1):1911-21. Disponível em: <https://dialnet.unirioja.es/servlet/articulo?codigo=5555932>. 


\section{ATUAÇÃO DE RESIDENTES DE ENFERMAGEM OBSTÉTRICA EM UM GRUPO DE GESTANTES: RELATO DE EXPERIÊNCIA}

Nayla Laís Ferreira Mazzetto*, Janaína Ramos Martins, Ana Vanessa Deffaccio Rodrigues, Maria Aparecida Moreira

*Autarquia Municipal de Saúde de Apucarana-AMS, Apucarana-PR, e mail: naaymazzetto@hotmail.com

INTRODUÇÃO: O ciclo vital feminino é marcado por diferentes fases, dentre elas a gestação, período pelo qual a mulher vivencia inúmeras transformações fisiológicas, físicas e emocionais. Tais mudanças podem gerar medo, insegurança, curiosidade e fantasias. Por se tratar de um momento significativo da vida de uma mulher, os profissionais da saúde podem atuar de forma integral proporcionando suporte, de modo a instrumentalizá-la e empoderá-la para vivenciar a gestação de forma mais segura e com maior qualidade. OBJETIVO: Relatar a atuação de residentes de enfermagem obstétrica em um grupo de gestantes de uma Unidade Básica de Saúde do Norte do Paraná. MÉTODO: Estudo de natureza descritiva, tipo relato de experiência. $O$ grupo de gestantes foi realizado por residentes do Programa de Residência em Enfermagem Obstétrica da Autarquia Municipal de Saúde de Apucarana-PR em conjunto com uma equipe de residentes (dentista, educador físico, fisioterapeuta, nutricionista e psicóloga) da Atenção Básica e profissionais da Estratégia Saúde da Família da mesma instituição (médico e agente comunitário de saúde), no mês de julho de 2018, realizado em três encontros, divididos semanalmente. RESULTADOS: Participaram do grupo nove gestantes e seus respectivos acompanhantes. O grupo foi conduzido por meio de trocas de experiências, onde os participantes tiveram participação efetiva em todo o processo. As temáticas discutidas foram: alterações fisiológicas e alimentação na gestação, acompanhamento odontológico, sinais de trabalho de parto, tipos de partos e posições, leis que amparam as gestantes, parturientes e puérperas, visita guiada na maternidade, cuidados com o bebê, aleitamento materno e depressão pós-parto. Evidenciou-se que o método utilizado durante o grupo foi capaz de fornecer orientações consistentes, pois proporcionou trocas entre todos os envolvidos, sanou dúvidas e cumpriu o principal objetivo de preparar as gestantes para o período gravídico-puerperal, minimizando medos e ansiedades. $\mathrm{Na}$ prática, foi possível perceber que a atuação da enfermagem obstétrica em conjunto com os demais profissionais desmistificou padrões instituídos de forma a encorajar a mulher ao seu protagonismo e singularidade nesse momento único e tão esperado. Ao final do grupo, o feedback foi positivo, o que nos mostra a necessidade do fortalecimento do vínculo com as gestantes, nos impulsionando a replicar esta experiência. CONCLUSÃO: As orientações e vinculação da equipe multiprofissional com a gestante e acompanhante promove o empoderamento e fortalece o protagonismo da mulher, minimizando a ansiedade pelo desconhecimento sobre o período gravídico-puerperal. Ainda, estabelece novas bases para o relacionamento entre profissionais, gestantes e sua rede de apoio. Faz-se necessário que estas atividades sejam estimuladas, pois é um recurso eficaz na abordagem das gestantes e seus familiares.

DESCRITORES: Enfermagem obstétrica; Gestantes; Atenção primária à saúde. 


\section{Obstétrica,2019;09-67}

\section{REFERÊNCIAS}

BRASIL. Ministério da Saúde. Secretaria de Estado da Saúde. Caderno da atenção básica. Atenção ao Pré-Natal de Baixo Risco. Brasília 2012.

SANFELICE, C. et al. Saberes e práticas de cuidado de gestantes de uma unidade básica de saúde. Revista de Enfermagem Online. v. 7, n.12, p. 6790-6799, 2013. 


\section{ATUAÇÃO DE RESIDENTES EM ENFERMAGEM OBSTÉTRICA EM UMA MATERNIDADE DE ALTO RISCO: RELATO DE EXPERIÊNCIA}

Janaína Ramos Martins*, Nayla Lais Ferreira Mazzetto, Maria Aparecida Moreira, Ana Vanessa Deffaccio Rodrigues

*Autarquia Municipal de Saúde de Apucarana-AMS, Apucarana-PR, e mail:
janaramos7@hotmail.com

INTRODUÇÃO: A gestação é uma fase muito importante e significativa na vida de uma mulher e vem permeada de intensas mudanças e transformações. A atenção obstétrica no Brasil ainda está focada no modelo biomédico, o que contribui para o aumento de procedimentos invasivos e intervencionistas durante o trabalho de parto. Sabemos que o parto é um momento esperado e ao mesmo tempo temido, carregado de significados culturais e de experiências por elas vivenciadas, geralmente baseadas em situações anteriores, em informações obtidas de pessoas leigas, em reportagens da mídia e em materiais informativos. OBJETIVO: Relatar a vivência de residentes em enfermagem obstétrica, na assistência ao processo de trabalho de parto e parto em uma maternidade de alto risco, da região Norte do Estado do Paraná. MÉTODO: Estudo de natureza descritiva, tipo relato de experiência, realizado por enfermeiras residentes do Programa de Residência em Enfermagem Obstétrica da Autarquia Municipal de Saúde de Apucarana-PR. O campo escolhido para apresentar a experiência foi uma Maternidade Referência para Alto Risco e que é cenário de prática para o Programa. RESULTADOS: Torna-se evidente que a assistência oferecida pelas residentes promove benefícios positivos nesse processo de trabalho de parto e parto. $\mathrm{O}$ apoio e orientações oferecidos por essas profissionais, tanto para a parturiente quanto para o acompanhante de sua escolha, torna o processo de parturição menos angustiante. Se tratando de uma maternidade de alto risco, muitas vezes têm a visão de que todos os partos precisem de intervenção cirúrgica. No entanto, o cuidado e atenção qualificada permitem que sua evolução ocorra de forma natural e garante detecção precoce de possíveis complicações. Dentre as ações executadas pelas residentes, a utilização dos métodos não farmacológicos tem se mostrado exitosas, tanto no quesito de alívio da dor, diminuição da ansiedade, auxílio na progressão e redução do tempo de trabalho de parto, quanto na restrição do uso de intervenções precoces e desnecessárias. Percebemos que o estímulo ao uso dos métodos não farmacológicos, a busca em proporcionar um ambiente acolhedor e o incentivo ao acompanhante como participante ativo, estimula a parturiente ao seu protagonismo e empoderamento, lhe trazendo segurança e confiança nessa fase, sendo capaz de promover uma experiência de parto positiva, mesmo que esse tenha um desfecho cirúrgico. Na prática, podemos afirmar o quanto a presença da residência pode contribuir beneficamente, promovendo avanço para o serviço e principalmente na experiência que as mulheres assistidas receberão. Ainda, quando esse modelo de assistência é associado ao trabalho em equipe observamos um avanço na qualidade da assistência prestada, pois promove trocas de experiências e a busca por um objetivo comum: a garantia de uma assistência de qualidade. CONCLUSÃO: A assistência oferecida pelas residentes, mostrou-se menos intervencionista, fornecendo suporte tanto clínico como emocional para as parturientes e acompanhantes, proporcionando uma experiência mais positiva no trabalho de parto e parto. 
DESCRITORES: Enfermagem Obstétrica; Obstetrícia; Parto.

\section{REFERÊNCIAS}

SEIDL, E. M. F. Expectativas de gestantes sobre o parto e suas percepções acerca da preparação para o parto. Temas psicologia. v. 24,n. 2,p. 681-693, jun. 2016. Disponível em http://pepsic.bvsalud.org/scielo.php?script=sci arttext\&pid=S1413389X2016000200015\&lng=pt\&nrm=iso Acesso: 10 maio 2019.

ANDRADE, L. F. B.; RODRIGUES, Q. P.; SILVA, R. C. V. Boas Práticas na atenção obstétrica e sua interface com a humanização da assistência. Revista Enfermagem UERJ. V. 25, 2017. Disponível em:https://www.epublicacoes.ueri.br/index.php/enfermagemueri/article/view/26442 Acesso:10 de maio de 2019. 


\section{ORIENTAÇÕES SOBRE AMAMENTAÇÃO PARA UM GRUPO DE GESTANTE: RELATO DE EXPERIÊNCIA}

Ana Carolina Pereira de Castro*, Milena Torres Guilhem Lago

*Centro Universitário Filadélfia, Unifil, Londrina-PR, e mail: anacarolinapereiracastro@gmail.com

INTRODUÇÃO: O leite materno é o alimento ideal para os bebês. A prática do aleitamento materno exclusive deve ser feita até o sexto mês de vida a qual influencia positivamente no crescimento e desenvolvimento adequado da criança. $O$ aleitamento materno promove vínculo, afeto, proteção e nutrição para a criança. A prática do aleitamento materno oferece grande impacto econômica para intervenção na redução da morbimortalidade infantil. Na gestação a mulher pode apresentar dúvidas, medos, fantasias e outros sentimentos que alimentam o senso comum, interferindo negativamente no cuidado prestado pelos profissionais de saúde, especialmente quando o saber científico é contraposto ao saber popular. OBJETIVO: Descrever as ações prestadas as gestantes por uma acadêmica de enfermagem na promoção do aleitamento materno em um grupo de gestantes. MÉTODO: Trata-se de um estudo na modalidade de relato de experiência, a partir da vivência de uma graduanda do curso de enfermagem com o grupo de gestantes que participam de um projeto em uma entidade filantrópica no norte do Paraná. RESULTADOS: A atividade foi desenvolvida com 13 gestantes, as idades variavam de 14 anos a 42 anos, cujo o objetivo era orientar através da palestra as gestantes em situação de vulnerabilidade promovendo a maternidade responsável. As mesmas foram bem receptivas a estratégia e tinham interesse pelo tema abordado. Entre as gestantes se encontravam primigestas e multigestas. Porém foi visível mesmo nos casos das gestantes que já amamentaram muitas dúvidas, mitos e receios de conseguirem ou não amamentar. Muitas relataram não entender algumas palavras que escutavam no pré-natal, e a maioria expressou desejo de doar leite materno. A atividade educativa se faz necessária pela importância de tratar assuntos que precisam de mais tempo para ser abordado com as gestantes, muitas vezes por falta de tempo e por uma demanda elevada, ficando poucas informações que possam estimular o Aleitamento Materno Exclusivo até os seis meses de idade durante as consultas de pré-natal. CONCLUSÃO: Estas atividades de ações educativas entre as gestantes são necessárias para que a assistência em saúde seja eficaz. Por ser um momento de troca de aprendizado a estratégia estimulou a participação das gestantes e esclareceu as dúvidas que muitas têm e às vezes esquecem de perguntar ao profissional durante a consulta de pré-natal. Através da atividade educativa é possível propiciar a essas mulheres orientações sobre os cuidados com o recém-nascido, conhecimento sobre o leite materno, proporcionando assim o empoderamento dessas gestantes para uma amamentação bem sucedida, além de promover uma troca de conhecimento entre as mesmas acerca do aleitamento materno.

DESCRITORES: Aleitamento Materno; Gestantes; Cuidado Pré-Natal. 


\section{Obstétrica,2019;09-67}

\section{REFERÊNCIAS}

VICARI, E.C. Aleitamento materno, a introdução da alimentação complementar e sua relação com a obesidade infantil. Revista Brasileira de Obesidade, Nutrição e Emagrecimento. v. 7, n. 40, p.72-83, 2013.

BRASIL. Ministério da Saúde. Secretaria de Atenção à Saúde. Departamento de Atenção Básica. Saúde da criança: nutrição infantil: aleitamento materno e alimentação complementar - Brasília: Editora do Ministério da Saúde, 2009. 


\section{EDUCAÇÃO EM SAÚDE SOBRE O AUTOEXAME DAS MAMAS: RELATO DE EXPERIÊNCIA}

Pamela Panas dos Santos Oliveira*, Kawany de Paula Lima, Daniela Biguetti Martins Lopes *Universidade Estadual de Londrina, Londrina-PR,
pamela panas@hotmail.com

INTRODUÇÃO: O câncer de mama é um crescimento descontrolado de células, que adquirem características anormais, causadas por uma ou mais mutações no seu material genético. O câncer de mama ocorre quase que exclusivamente em mulheres e é contemplado por uma das maiores campanhas de prevenção e conscientização, o Outubro Rosa. Esta campanha promove diversas ações, entre elas a educação em saúde para toda a comunidade, visando alertar todas as mulheres sobre as formas de prevenção do câncer de mama e câncer de colo do útero, e também a importância do diagnóstico precoce da doença. Dentre as formas de prevenção, a realização frequente do autoexame das mamas, ainda é um desafio para maior parte das mulheres. Sendo esse, um importante tema para se trabalhar com a população feminina. OBJETIVO: Relatar a experiência sobre educação em saúde realizada na campanha Outubro Rosa em uma Unidade Básica de Saúde da zona leste do Município de Londrina-PR. METODOLOGIA: Trata-se de um estudo de natureza descritiva, do tipo relato de experiência realizado em outubro de 2018. Com a iniciativa de uma docente de enfermagem da área de saúde da mulher, junto com o Centro Acadêmico de enfermagem Universidade Estadual de Londrina, foi desenvolvida uma ação social na campanha Outubro Rosa para mulheres atendidas na respectiva unidade de saúde. Esta ação envolvia atividades para conscientização sobre as formas de prevenção do câncer de mama e câncer de colo do útero, orientações para prevenção de doenças sexualmente transmissíveis, climatério e incontinência urinária. RESULTADOS: Nas orientações sobre a prevenção do câncer de mama, focamos a prevenção e o autoexame das mamas. Utilizamos protótipos para simular o passo a passo do autoexame, sempre enfatizando os sinais e sintomas que podem surgir, e conversamos com as mulheres sobre a importância de realizar o autoexame frequentemente, e buscar a ajuda de um profissional de saúde, caso encontre alguma alteração. A maior parte das mulheres com quem conversamos, relataram não realizar o autoexame por esquecimento, mas que o passo a passo em si do exame, era fácil de realizar. Já algumas mulheres relataram que realizam o autoexame sempre que podem, e que entendem a importância desta forma de prevenção. Foi possível esclarecer dúvidas das mulheres sobre o câncer de mama, as formas de prevenção, e estas tiveram a chance de realizar no protótipo o passo a passo do autoexame. Durante a atividades foi possível identificar erros, ensiná-las a forma correta do autoexame para identificar possíveis alterações. CONCLUSÃO: Apesar de a campanha Outubro Rosa ter bastante impacto na população, ainda precisamos enfatizar a importância do autoexame das mamas sempre que possível, infelizmente a implantação desta prática ainda é um desafio. Percebemos que ações como esta devem ser realizadas com maior frequência, e que na rotina do atendimento às mulheres, os profissionais de saúde devem implementar essa forma de prevenção, enfatizando que a realização do autoexame é um importante passo para prevenção e diagnóstico precoce do câncer de mama. 
DESCRITORES: Autoexame; Neoplasia da mama; Educação em saúde.

\section{REFERÊNCIAS}

PORTO, M. A. T. et al. Aspectos Históricos do Controle do Câncer de Mama no Brasil. Revista Brasileira de Cancerologia. p.1-9, 2013.

SCLOWITZ, M. L. et al. Condutas na prevenção secundária do câncer de mama e fatores associados. Revista Saúde Pública. p.1-10, 2003.

CAVALCANTE, S. A. M. et al. Ações do Enfermeiro no rastreamento e Diagnóstico do Câncer de Mama no Brasil. Revista Brasileira de Cancerologia. p.1-9, 2013.

Ministério da Saúde. Diretrizes para detecção precoce do câncer de mama no Brasil. Brasil: Instituto Nacional do Câncer, 2015. 


\section{CONHECIMENTO A PARTIR DA EXTENSÃO UNIVERSITÁRIA: RELATO DE EXPERIÊNCIA}

Isadora Santana Begale*, Keli Regiane Tomeleri da Fonseca Pinto

*Universidade Estadual de Londrina/UEL, Londrina-PR, e-mail: isabegale@gmail.com

INTRODUÇÃO: Os profissionais da área da saúde ao terem uma relação mais direta com os pacientes, acabam refletindo sobre as experiências de sua própria vivência pessoal, como os sentimentos vividos, o processo de enfermidade e os conflitos, refletidos pelo ser humano no qual presta os cuidados assistenciais. OBJETIVO: Descrever os conhecimentos adquiridos a partir da participação no Projeto de Extensão. MÉTODO: O projeto pretende contribuir para a promoção do parto e nascimento saudáveis e a prevenção da morbimortalidade materna e perinatal através das visitas das gestantes e seus acompanhantes a maternidade de alto risco. As visitas são realizadas na maternidade do Hospital Universitário do Norte do Paraná e são previamente agendadas durante a consulta de pré-natal. As atividades são desenvolvidas às sextas-feiras, das 14 às 18 horas, pelos alunos do curso de graduação de enfermagem e, além da visita orientada à maternidade e o acolhimento da gestante, são realizadas orientações de esclarecimento de dúvidas referentes à hospitalização da mulher e do recém-nascido, orientações sobre o papel do acompanhante e o procedimento para o registro do nascimento da criança. RESULTADOS: A participação no projeto de extensão me permitiu adquirir, produzir e analisar conhecimentos sobre o momento gestacional, seja pelo aprendizado proporcionado pelas professoras responsáveis, seja pelo senso comum das pacientes e de seus acompanhantes. A cada reunião é possível absorver algo novo, diferente, inusitado e mais importante, descobrir a relevância da profissão dentro da comunidade. Esse projeto nos faz acreditar que é na humanização da assistência que obtemos resultados melhores para o paciente, pois quando há um cuidado mais pessoal, o paciente deixa de ser tratado apenas como um mero corpo, e passa a ser visto como o todo complexo que ele é. CONCLUSÃO: Como estudante, percebo que a experiência oferece um reconhecimento pessoal ao discente, fazendo com que este se sinta realizado devido à assistência prestada.

DESCRITORES: Maternidade; Saúde da Mulher; Humanização da Assistência.

\section{REFERÊNCIAS:}

LOPES, LMM; SANTOS, SMP. [Florence Nightingale: notes on the founder of Modern Nursing]. Rev Enf Ref [Internet] 2010 [cited 2014 Nov 04];3(2):181-9. Available from: http://www. index-f.com/referencia/2010pdf/32-181.pdf Portuguese.

MOTA, Roberta Araújo; MARTINS, CG de M.; VÉRAS, Renata Meira. Papel dos profissionais de saúde na política de humanização hospitalar. Psicologia em estudo, v. 11, n. 2, p. 323-330, 2006. 


\title{
21. PROJETO DE EXTENSÃO VISITA À MATERNIDADE: RELATO DE EXPERIÊNCIA
}

\author{
Bruna Acioli Pieri ${ }^{\star}$, Keli Regiane Tomeleri da Fonseca Pinto \\ *Universidade Estadual de Londrina/UEL, Londrina-PR. E-mail: \\ bruna.pieri.acioli@gmail.com
}

INTRODUÇÃO: As mulheres são a maioria da população brasileira e as principais usuárias do Sistema Único de Saúde. Para incorporar as práticas de atenção à saúde da mulher, o Ministério da Saúde lançou o Programa de Assistência Integral à Saúde da Mulher. Dentre as propostas o programa está incluído ações educativas, preventivas, de diagnóstico, tratamento e recuperação, englobando a assistência à mulher em clínica ginecológica, no pré-natal, parto e puerpério, além de outras necessidades. Visando contemplar e melhorar a ações voltadas para a atenção integral da mulher, principalmente na fase da gravidez, proporcionando alívio e conforto para as mulheres, foi proposto o projeto Visita a maternidade de alto risco, conhecendo o desconhecido, para que as gestantes de alto risco, pudessem ter o primeiro contato com a maternidade. OBJETIVO: Descrever a experiência de uma acadêmica de enfermagem participante de um projeto de extensão na maternidade de alto risco do Hospital universitário de Londrina. MÉTODOS: Trata-se de um relato de experiência. O projeto é desenvolvido na maternidade do Hospital Universitário de Londrina, todas as sextas-feiras a tarde, com visitas agendadas das gestantes, com o objetivo de diminuir a ansiedade e tirar as dúvidas das gestantes. RESULTADOS: A estudante de enfermagem pode vivenciar e compreender melhor o processo de assistência à saúde da mulher enquanto participante do projeto de extensão. A gravidez é uma fase muito importante e delicada na vida da mulher, especialmente quando fatores maternos e/ou fetais tornam essa gravidez de risco. Nesta situação a ansiedade e preocupação da mulher se agrava, fazendo-se necessária ações que permitam deixá-la mais aliviada. As principais atividades do projeto compreendem passar informações para a mãe, orientando sobre o tipo de parto, papel do acompanhante, amamentação, rotinas hospitalares, esclarecendo dúvidas, entre outras atividades. Este período foi extremamente importante para entender o papel do enfermeiro como porta voz e fator chave para tranquilizar a mulher. CONCLUSÃO: O projeto de extensão visita a maternidade de alto risco, proporcionou uma maior aproximação da estudante com as gestantes, fazendo-a assimilar seu conhecimento teórico com a prática humanizada da assistência.

DESCRITORES: Enfermagem; Ensino; Saúde da mulher.

\section{REFERÊNCIAS:}

PARANÁ, Secretaria de Estado da Saúde do Paraná. Linha Guia Rede Mãe

Paranaense, 7 ed, Paraná, 2018. 


\title{
22. RELATO DE EXPERIÊNCIA SOBRE ESTÁGIO EXTRACURRICULAR EM UMA MATERNIDADE DE ALTO RISCO
}

\author{
Emily Marques Alves*, Keli Regiane Tomeleri da Fonseca Pinto
}

*Universidade Estadual de Londrina, Londrina-PR, E-mail: marquesalvesemily@gmail.com

INTRODUÇÃO: O estágio extracurricular é aquele realizado de forma voluntária pelo aluno, visando o aperfeiçoamento profissional, além de uma aproximação ainda maior e mais realista com uma área específica da enfermagem na qual tem afinidade. A gestação é um momento muito especial na vida da mulher e das pessoas próximas a ela. Porém como correm muitas mudanças neste momento, podem surgir sentimentos positivos e negativos, dessa forma uma assistência humanizada e de qualidade deve ser prestada, e para isso os profissionais devem ser bem qualificados. OBJETIVO: Descrever a experiência de uma estudante de enfermagem frente a um estágio extracurricular em uma maternidade de alto risco. MÉTODO: Trata-se de um relato de experiência referente a realização de um estágio extracurricular na Maternidade de Alto Risco do Hospital Universitário de Londrina. Com supervisão direta das enfermeiras plantonistas da unidade. O período de realização do estágio foram 15 dias do mês de janeiro de 2019. RESULTADOS: Durante todo o período do estágio, foi possível acompanhar diversas mulheres desde a sua admissão, pré-parto, parto, puerpério até a alta hospitalar. Sendo assim, foi realizada junto a enfermeira, a Sistematização da Assistência de Enfermagem, auxílio em procedimentos como o Cateterismo Vesical, Teste do Pezinho. Foi possível assistir a dois partos durante o período, realizando um apoio emocional durante o trabalho de parto e parto. Houve um contato e abordagem maior com as puérperas internadas, auxiliando nos cuidados com RN, como o primeiro banho, que é um momento de tensão entre as mulheres e até mesmo para os familiares, orientações e manejo em relação ao aleitamento materno e o apoio emocional principalmente para aquelas puérperas internadas a mais tempo, devido a algum tipo de complicação tanto relacionado a ela, quanto ao bebê, realizando a prática de terapias complementares para o relaxamento. CONCLUSÃO: Portanto, apesar de um curto período de tempo, a vivência foi importante para a formação profissional da estudante, tendo a oportunidade de acompanhar o trabalho de enfermeiras obstetras, e assim complementar os conhecimentos adquiridos em aulas e estágios da matriz curricular. Além de que reforçou a vontade da estudante de seguir a área da obstetrícia para poder realizar uma assistência integral, humanizado e assim de qualidade.

DESCRITORES: Gestação, Educação em Enfermagem; Obstetrícia

\section{REFERÊNCIAS:}

ALMEIDA, S.A. et al. As contribuições do estágio extracurricular na formação acadêmica de alunos de enfermagem em um ambulatório de uma instituição privada de ensino em Belo Horizonte - MG: relato de experiência. Belo Horizonte, MG, v.02, n.03, ago/set de 2012.

RIOS C.T.F, VIEIRA N.F.C. Ações educativas no pré-natal: reflexão sobre a consulta de enfermagem como um espaço para educação em saúde. Ciência \& Saúde Coletiva 12 (2):477-486. 
Obstétrica,2019;09-67

\section{ATIVIDADE EXTENSIONISTA: O SIGNIFICADO PARA O ALUNO DA GRADUAÇÃO}

Sara de Fátima Oliveira*, Keli Regiane Tomeleri da Fonseca Pinto

*UNIVERSIDADE ESTADUAL DE LONDRINA, Londrina-Pr, e mail: saa.f.oliveira@gmail.com

INTRODUÇÃO: A extensão universitária é uma forma de interação entre a universidade e a comunidade, por meio de atividades de promoção da saúde. A experiência vivenciada pelos alunos é de grande valia para o desenvolvimento pessoal e profissional. OBJETIVO: Descrever o significado da participação do aluno no projeto de extensão "Visita à maternidade de alto risco". MÉTODO: Trata-se de um estudo descritivo, tipo relato de experiência. O projeto de Extensão é desenvolvido na Maternidade do Hospital Universitário do Norte do Paraná, desde julho de 2017. As visitas são previamente agendadas durante as consultas de pré-natal que são realizadas no Ambulatório de Especialidades do Hospital Universitário. As atividades são desenvolvidas às sextas-feiras, no período vespertino, pelos alunos da graduação do curso de Enfermagem da Universidade Estadual de Londrina, acompanhados por um docente da área de Saúde da Mulher. RESULTADOS: A participação neste projeto como discente, proporciona ampliação na área do conhecimento, pois temos contato com conteúdos ainda não vistos na graduação, além da integração com docentes da área de Saúde da Mulher e enfermeiras obstetras que transmitem conhecimento através da troca de saberes. Ajuda nas relações interpessoais entre alunos professores, gestantes e seus respectivos acompanhantes por meio de uma roda de conversa, para esclarecimento de dúvidas, neste momento é imprescindível uma comunicação de forma clara e precisa para que as informações e orientações sejam entendidas de forma integral, devido e este fator podemos então aprimorar nossa forma de comunicação, tendo em vista que a Enfermagem necessita deste meio para um atendimento efetivo e de qualidade. Como estudante, o projeto ajuda no desenvolvimento pessoal e profissional, bem como a ampliação do olhar sobre as situações nas quais se pode intervir a fim de obter uma humanização da assistência ao parto e nascimento. E particularmente criei uma admiração ainda maior do que já possuía previamente, pela área de Enfermagem obstétrica. Ao receber relatos de puérperas, de como o projeto ajudou para alívio da ansiedade e estresse no período antes do nascimento, gera um sentimento de felicidade e satisfação que advém deste retorno positivo. CONCLUSÃO: O projeto propicia crescimento profissional através do incentivo a busca por conhecimento, em razão dos temas trabalhados serem incitantes. E crescimento pessoal pela vivencia em ações de humanização que resulta em sentimentos de gratidão e felicidade.

DESCRITORES: Saúde da mulher; Gestação; Maternidade.

\section{REFERÊNCIAS}

SOUZA, S.; GUALDA, D. A experiência da mulher e de seu acompanhante no parto em uma maternidade pública. Curitiba, 2016. Disponível em: http://www.scielo.br/pdf/tce/v25n1/0104-0707-tce-25-01-4080014.pdf. Acesso em: 24 maio 2019. 


\section{CONSULTA DE PRÉ-NATAL POR ENFERMEIRAS RESIDENTES: RELATO DE EXPERIÊNCIA}

Renata Portero Wielganczuk*, Laís de Lima Oliva, Eliseth Krupa Almeida, Keli Regiane Tomeleri da Fonseca Pinto

*Universidade Estadual de Londrina, Londrina-PR, e mail: reeportero@hotmail.com

INTRODUÇÃO: A assistência pré-natal tem o objetivo assegurar que o binômio mãefilho tenha condições favoráveis a um desfecho saudável do período gestacional. Esse acompanhamento constitui um rol de cuidados, condutas e procedimentos em prol da mulher grávida e do concepto, que tem como objetivo principal a redução a morbimortalidade materna e fetal. Portanto, faz-se necessário um acolhimento adequado da gestante por parte de toda a equipe de saúde, fornecendo apoio e confiança para que possam acompanhar com maior autonomia e tranquilidade sua gestação, parto e puerpério. É de extrema importância o papel enfermeiro junto a outros profissionais no acompanhamento dessas mulheres, na tentativa de melhorar o nível assistencial às mulheres no ciclo grávido-puerperal. Colaborando assim, para minimizar as intercorrências obstétricas, assegurando o bem-estar físico e mental da mãe e bebê. A consulta de enfermagem no atendimento pré-natal, constitui um dos grandes recursos para a contribuição da ampliação da cobertura assistencial ás gestantes. É importante destacar, que esta deve estar assegurada nos princípios da Educação em Saúde, valorizando a integralidade da assistência à mulher, a fim de favorecer sua qualidade de vida. É fundamental que se desenvolva ações associando as práticas assistenciais e educativas valorizando o saber popular, as necessidades da mulher, a fim de que elas sejam assistidas de maneira integral. OBJETIVO: Descrever a experiência de residentes de enfermagem obstétrica no atendimento pré-natal durante a consulta de enfermagem em uma Unidade Básica de Saúde em Londrina-PR MÉTODO: Trata-se de um relato de experiência sobre a prática vivencial de enfermeiras residentes na realização de abertura e consulta subsequente de pré-natal em uma Unidade Básica de Saúde em Londrina-PR. RESULTADOS: Durante as consultas de pré-natal as residentes realizam o acolhimento às gestantes e seus acompanhantes, realizam a escuta ativa, fornecem orientações da cerca da gestação, as mudanças comuns no organismo nessa fase, alimentação adequada, prática de exercícios físicos, conferem a vacinação e solicitam exames. É realizado também o exame físico obstétrico e sanadas as dúvidas que surgem no decorrer da consulta. Nas consultas finais às gestantes são orientadas sobre a importância da visita na maternidade e esclarecido dúvidas sobre trabalho de parto e parto. Durante a consulta também é efetuado o preenchimento dos impressos e da carteira da gestante e ao final da consulta realizada a evolução de enfermagem no prontuário. CONCLUSÃO: A atuação no enfermeiro na realização do pré-natal possibilita a formação de vínculo com a gestante, propiciando o desenvolvimento de medidas favoráveis que visam a abordagem apropriada às necessidades individuais das gestantes. Possibilitando o acompanhamento do estado de saúde e bem estar da gestante e do desenvolvimento fetal, promovendo a detecção precoce de prováveis problemas. A experiência demonstra que além de todo o conhecimento científico necessário para a realização da consulta, deve-se ter muita empatia, respeito e amor, para que os resultados sejam satisfatórios para ambas as partes e se tenha um reconhecimento e visibilidade do papel realizado. 
DESCRITORES: Cuidado Pré-Natal; Gestantes; Obstetrícia.

\section{REFERÊNCIAS:}

LEAL, N.J; BARREIRO, M.S.C; MENDES, R.B; et al. Assistência ao pré-natal: depoimento de enfermeiras. Rev Fund Care Online. 2018 jan./mar.; 10(1):113-122.

ROCHA, A.C; ANDRADE, G.S. Atenção da equipe de enfermagem durante o pré-natal: percepção das gestantes atendidas na rede básica de Itapuranga- GO em diferentes contextos sociais. Revista Enfermagem Contemporânea. 2017 Abril;6(1):30-41 
Obstétrica,2019;09-67

\title{
25. INSERÇÃO DO DISCENTE DO CURSO DE ENFERMAGEM NA PROMOÇÃO DO CUIDADO CANGURU: RELATO DE EXPERIÊNCIA
}

\author{
Paola Ramos Silvestrim*, Gabriela Ramos Ferreira Curan
}

*Universidade Estadual de Londrina, Londrina-PR, e mail: paolarsilvestrim@gmail.com

INTRODUÇÃO: As vivências intra-hospitalares ocorrem de maneira gradual e crescente pelos alunos nos cursos de Enfermagem. Além dos momentos previstos na grade do curso em si, a participação do acadêmico em projetos de pesquisa pode viabilizar a ampliação das vivências junto ao paciente e sua família, corroborando com a aquisição de habilidades técnico-científicas e sociais. Nesse contexto, relata-se a experiência de uma acadêmica de Enfermagem na abordagem às mães de recémnascidos prematuros para a promoção do cuidado canguru, a partir de sua inserção em um projeto de pesquisa desenvolvido em uma unidade neonatal. OBJETIVO: Relatar a experiência 1) da participação pelo aluno do segundo ano do curso de graduação em Enfermagem em um projeto de pesquisa desenvolvido no cenário de uma unidade neonatal; 2) da promoção junto às mães do contato pele-a-pele e do cuidado canguru pela perspectiva deste aluno. MÉTODO: Trata-se de um relato de experiência realizado por uma acadêmica do segundo ano de Enfermagem durante sua participação no projeto de pesquisa intitulado "Cuidado Canguru contínuo e prolongado: uma possibilidade protetora para a resistência microbiana em prematuros?", iniciado em dezembro de 2016, atualmente ainda em andamento. O projeto é realizado na Unidade Neonatal de um hospital universitário do Paraná. A participação da graduanda no projeto iniciou-se em Maio de 2018. Participam do projeto mães que cujos bebês apresentam peso de nascimento inferior a $2500 \mathrm{~g} \mathrm{e}$ idade gestacional inferior a 37 semanas. RESULTADOS: A vivência em uma atividade extracurricular é algo desejado por grande parte dos alunos de graduação, e especialmente na Enfermagem, o desejo de estar em contato direto com o paciente e sua família é muitas vezes anterior à possibilidade de concreta prevista no currículo do curso. Tratando-se do recém-nascido prematuro internado em uma unidade neonatal, este contato torna-se ainda mais distante das possibilidades comuns para os acadêmicos, sendo muitas vezes pontual ou até mesmo inexistente no curso de graduação. A participação no projeto de pesquisa em questão possibilitou à aluna do segundo ano de graduação o contato com a Maternidade de alto risco e com a Unidade Neonatal, contribuindo para desmistificar estes ambientes hospitalares e observar sua dinâmica. A abordagem às mães para participação na pesquisa demandou preparo e apropriação por parte da aluna aos princípios do Método Canguru - benefícios do contato pele a pele com o bebê no estímulo ao aleitamento materno, no ganho de peso, no fortalecimento do vínculo e sobre aspectos da microbiota da pele materna e do bebê. Paralelamente, a aluna exercita e aprimora suas habilidades de comunicação e construção de vínculo terapêutico, despertando sua autopercepção enquanto possível influenciadora de práticas e atitudes na família do recém-nascido. Registra-se o sentimento de empoderamento da graduanda, pela capacidade de promover este cuidado. CONCLUSÃO: A experiência da acadêmica de Enfermagem na abordagem às mães de recém-nascidos prematuros para a promoção do cuidado canguru, a partir de sua inserção em um projeto de pesquisa, foi enriquecedora nos aspectos da relação interpessoal e comunicação, ampliando a percepção de possibilidades de atuação profissional, sendo relevante para a formação. 
DESCRITORES: Enfermagem; Método Canguru; Recém-Nascido Prematuro; Relações Mãe-Filho.

\section{REFERÊNCIAS}

MINISTÉRIO DA SAÚDE. Método canguru: diretrizes do cuidado. $1^{\underline{a}}$ ed. Brasília, 2018. Disponível em: <http://portaldeboaspraticas.iff.fiocruz.br/wpcontent/uploads/2018/09/metodo canguru diretrizes cuidado2018.pdf $>$ Acesso em 20 de maio de 2019.

MAIA, J.A.; OLIVEIRA, M, P.; FURTADO, S.S.; SILVA, L.M.; PEREIRA, M.L.B. Método Canguru: a importância da família na recuperação do recém-nascido de baixo peso. Revista Enfermagem em foco - COFEN. v. 2, n.4, p. 231-234, 2011. 


\section{A MULTIDISCIPLINARIDADE DO PLANEJAMENTO REPRODUTIVO NA UNIDADE BÁSICA DE SAÚDE}

Brenda Rafaella da Silva Magalhães*, Edilaine Fungari Cavalcante, Jossane Julie Pereira, Juliana Sousa de Almeida, Ester Massae Okamoto Dalla Costa

*Universidade Estadual de Londrina, Londrina-PR, e mail: brendamagalhaes@gmail.com

INTRODUÇÃO: O planejamento reprodutivo baseia-se no respeito aos direitos sexuais e reprodutivos, sendo frequente a utilização errônea desse termo no uso estrito ao sinônimo de controle de natalidade, uma vez que a atenção deve estar voltada tanto para a anticoncepção quanto para a concepção. A atuação do profissional de saúde deve estar pautada na Lei no 9.263, de 12 de janeiro de 1996 que regulamenta o $\S 7^{0}$ do artigo 226 da Constituição Federal, que envolve o aconselhamento e atividades educativas e clínicas na Atenção Primária de Saúde. OBJETIVO: O resumo discute a importância das orientações e condutas da equipe multidisciplinar no planejamento reprodutivo na Unidade Básica de Saúde. MÉTODO: Relatamos a experiência vivenciada pela farmacêutica, pelo profissional de educação física e pelas enfermeiras das Residências Multiprofissional em Saúde da Mulher e Enfermagem Obstétrica da Universidade Estadual de Londrina em uma Unidade Básica de Saúde da cidade de Londrina/PR, no mês de abril e maio de 2019. RESULTADOS: Foram atendidas 19 usuárias, todas previamente entrevistadas pela equipe multiprofissional e avaliadas de acordo com fatores individuais e contexto de vida no que diz respeito ao estado de saúde, condições econômicas, características da usuária, fase da vida, padrão de comportamento sexual e fatores culturais. Também foram avaliadas características dos métodos anticoncepcionais quanto à eficácia, efeitos secundários, aceitabilidade, disponibilidade, facilidade de uso, reversibilidade e proteção contra Infecções Sexualmente Transmissíveis. Após a oferta dessas informações à usuária, a mesma escolheu o método anticoncepcional de sua preferência, respeitando o princípio de autonomia e assistência à saúde sem preconceitos ou privilégios ofertados pelos profissionais de saúde nesse momento oportuno de oferta humanizada na atenção do Sistema Único de Saúde. CONCLUSÃO: Além dos critérios de elegibilidade para uso de métodos anticoncepcionais desenvolvidos pela Organização Mundial da Saúde e divulgação de direitos sexuais e reprodutivos, é fundamental discutir a autonomia da vontade e escolha de tratamento pelo usuário, conscientizando-o por meio de informações e incentivando-o a considerar a corresponsabilidade entre si e o(s) profissional(ais) de saúde, o vínculo estabelecido e o empoderamento em relação ao planejamento reprodutivo adotado durante a consulta compartilhada.

DESCRITORES: Saúde da Mulher; Equipe Multiprofissional; Direitos Sexuais e Reprodutivos.

\section{REFERÊNCIAS}

BRASIL. Ministério da Saúde. Saúde Sexual e Saúde Reprodutiva: Cadernos de Atenção Básica. Brasília: Ministério da Saúde; 2013. 


\section{Obstétrica,2019;09-67}

LONDRINA. Prefeitura do Município. Autarquia Municipal de Saúde. Planejamento Familiar: Protocolo Clínico de Saúde da Mulher. Londrina: Secretaria Municipal de Saúde; 2006.

OSIS, MJD. et al. Atenção ao planejamento familiar no Brasil hoje: reflexões sobre os resultados de uma pesquisa. Cadernos de Saúde Pública, Rio de Janeiro, v. 22, n. 11, p. 2481-2490, nov. 2006.

PIERRE, LAS; CLAPIS, MJ. Planejamento familiar em Unidade de Saúde da Família. Revista Latino-Americana de Enfermagem. v. 6, n. 18, 2010.

SILVA, RM. et al. Planejamento familiar: significado para mulheres em idade reprodutiva. Ciência e saúde coletiva. v. 16, n. 5, p. 2415-2424, 2011. 


\section{USO DE MEDICAMENTOS NA GRAVIDEZ, NO PUERPÉRIO E NA LACTAÇÃO: O FARMACÊUTICO NA AVALIAÇÃO DE RISCOS}

Brenda Rafaella da Silva Magalhães*, Sandro Cesar Feliciano, Ester Massae Okamoto Dalla Costa

*Universidade Estadual de Londrina, Londrina-PR, e mail: bm.brendamagalhaes@gmail.com

INTRODUÇÃO: O uso de medicamentos na gestação e na lactação sempre foi tema para esclarecimento de dúvidas da comunidade e dos profissionais de saúde justamente por se tratar de condutas que podem facilmente expor a mulher e o concepto aos efeitos farmacológicos que podem apresentar ações potencialmente danosas, seja através da barreira placentária ou pelo leite materno. Muitas gestantes, puérperas e lactantes não conhecem os riscos sobre o uso de medicamentos e a carência de informações pode dificultar o uso responsável dos mesmos, motivo de grande preocupação pois os agravos que podem ocorrer às usuárias refletem como um sério problema de saúde pública. OBJETIVO: O resumo discute a atuação do farmacêutico na avaliação de riscos no uso de medicamentos durante o período gestacional, puerperal e durante a lactação. MÉTODO: Relatamos a experiência vivenciada pela farmacêutica da Residência Multiprofissional em Saúde da Mulher da Universidade Estadual de Londrina e pelo farmacêutico do Núcleo de Apoio à Saúde da Família responsável na Unidade Básica de Saúde da cidade de Londrina/PR. RESULTADOS: A classificação de risco de medicamentos para uso na gravidez estabelecida pela Food and Drug Administration (FDA) que categoriza os medicamentos em cinco categorias $(A, B, C, D$ e $X)$ é uma ferramenta que o farmacêutico utiliza durante as atividades de Assistência Farmacêutica nas consultas individuais e coletivas. É dever do farmacêutico prevenir, identificar e avaliar riscos referentes ao uso desses medicamentos e realizar intervenções juntamente de outros membros da equipe de saúde em prol da qualidade de assistência ofertada às mulheres. CONCLUSÃO: A atuação do farmacêutico está pautada no esclarecimento sobre o uso de medicamentos, especialmente quando se trata de medicamentos utilizados durante a gravidez, no puerpério e na lactação. Devem ser esclarecidas as dúvidas tanto das mulheres quanto de profissionais de saúde que estão envolvidos no processo de cuidado dessas usuárias. A promoção desse profissional é fundamental na inserção do contexto multidisciplinar na integração de informações assistenciais.

DESCRITORES: Saúde da Mulher; Equipe Multiprofissional; Assistência Farmacêutica.

\section{REFERÊNCIAS:}

BRASIL. Ministério da Saúde. Amamentação e uso de medicamentos e outras substâncias. Brasília: Ministério da Saúde; 2010.

BRASIL. Ministério da Saúde. Práticas Farmacêuticas no Núcleo Ampliado de Saúde da Família a Atenção Básica (Nasf AB). Brasília: Ministério da Saúde; 2018.

OSORIO-DE-CASTRO, CGS; PAUMGARTTEN, FJR; SILVER, LD. O uso de medicamentos na gravidez. Ciência e saúde coletiva. v. 9, n. 4, p. 987-996, 2004. 


\section{A VIVÊNCIA DE ESTUDANTES DE ENFERMAGEM EM UMA MATERNIDADE PÚBLICA: RELATO DE EXPERIÊNCIA}

Vanderson Renan Alves Queiroz*, Izabel Dayana de Lemos Santos

*Pitágoras, Londrina-PR, e mail: vanderson.alves@hotmail.com

INTRODUÇÃO: nos últimos anos têm se investido em evidências científicas para assistência materno infantil, do manejo clínico até a humanização no atendimento, porém, ainda muito tem que ser percorrido para estabelecer uma assistência de qualidade e para isso é necessário investir na educação dos profissionais que futuramente vão atender essa população. O investimento na formação e atualização profissional é fundamental para constituir uma prática pautada em evidências científicas, por isso, a importância de colocar em ação o conhecimento adquirido na teoria inovadora. OBJETIVO: relatar a experiência de discentes do curso de graduação em enfermagem em práticas de atendimento materno infantil em uma maternidade pública. MÉTODO: estudo descritivo do tipo relato de experiência, acerca da vivência na disciplina saúde da mulher, no sétimo semestre, de um curso de graduação em enfermagem, realizada em uma maternidade pública, desta forma, de atendimento exclusivo ao Sistema Único de Saúde, de um município do norte do Paraná, no período de outubro de 2017. RESULTADOS: a vivência ofereceu aos discentes, oportunidades para realizar práticas discutidas em teoria, por meio das seguintes habilidades: ausculta de batimento cardiofetal; leitura de cardiotocografia; praticas obstétricas não farmacológicas de alívio da dor; manejo do puerpério imediato; incentivo do aleitamento materno exclusivo; cuidados com recém-nascido. Assim, aprimorando o conhecimento a respeito da assistência de enfermagem na área materno infantil, além de proporcionar um momento de esclarecimento para os discentes a partir da monitoria em campo de um docente graduado e especializado na área. CONCLUSÃO: evidenciou-se que o estudo foi relevante para os estudantes, pois contribuiu para assimilar conhecimentos na prática e proporcionou crescimento para formação profissional, assim como proximidade de uma assistência de enfermagem pautada em evidências científicas e humanizada no âmbito do atendimento materno infantil no SUS.

DESCRITORES: Maternidades; Enfermagem Materno Infantil; Estudantes de Enfermagem.

\section{REFERÊNCIAS:}

ALVES, R. C.; RUFINO, J. V.; CAPELLO, T.C.; CATHARINO, A. L. G.; MEDEIROS, F.F. Atuação de uma equipe multiprofissional na assistência pré-natal e puerperal: um relato de experiência Revista Saúde. Com. V. 14, n. 3, p. 1280-1283, 2018.

WHO recommendations: intrapartum care for a positive childbirth experience. Geneva: World Health Organization. Licence: p 4-212, 2018.

BRASIL. Ministério da Saúde. Diretriz nacional de assistência ao parto normal. Comissão Nacional incorporação de tecnologias do SUS/ CONITEC. Secretaria de Ciência, Tecnologia e Insumos Estratégicos Esplanada dos Ministérios, Brasília - DF, 2016. 


\section{CONSULTA COMPARTILHADA E O CUIDADO INTEGRAL À SAÚDE DA MULHER: RELATO DE EXPERIÊNCIA}

Edilaine Fungari Cavalcante*, Brenda Rafaella da Silva Magalhães, Debora Lydines Martins Corsino, Kelly Cristiane Michalichen, Rosely Jung Pisicchio, Clisia Mara Carreira

*Universidade Estadual de Londrina, Londrina-PR, e mail: edilainefungari@gmail.com

INTRODUÇÃO: As mulheres são as principais usuárias do Sistema Único de Saúde, nesse sentido, oferecer um atendimento de qualidade pode reduzir o agravo de doenças e melhorar sua condição de saúde. Entre as diferentes formas de atendimento previsto nos cadernos de atenção básica, a consulta compartilhada é uma estratégia efetiva para cuidar integralmente da saúde da mulher. OBJETIVO: Descrever a experiência vivenciada nas consultas compartilhadas por uma equipe da residência multiprofissional de saúde da mulher. MÉTODO: Este trabalho é um relato de experiência. A equipe multiprofissional é composta pelas seguintes áreas: Educação Física, Farmácia, Nutrição e Psicologia. As consultas compartilhadas foram realizadas no Ambulatório Multiprofissional de Atenção à Saúde da Mulher, localizado dentro do Ambulatório de Especialidades do Hospital Universitário de Londrina-PR. RESULTADOS: As mulheres foram encaminhadas para o Ambulatório Multiprofissional de Atenção à Saúde da Mulher a partir de uma especialidade clínica do Ambulatório de Especialidades e a primeira consulta multiprofissional teve duração de aproximadamente 60 minutos, com o objetivo de acolher a usuária e conhecer seu histórico de saúde, psicossocial e hábitos de vida. As principais demandas identificadas foram: doenças metabólicas, reumáticas e psiquiátricas; planejamento reprodutivo, modificação do estilo de vida, adesão a farmacoterapia e questões emocionais. A partir do olhar das quatro áreas profissionais e da discussão do caso, era priorizada para acompanhamento as demandas prioritárias da usuária, e quando necessário, consultas com uma área específica era agendada para complementar as orientações de intervenção. CONCLUSÃO: A experiência vivenciada demonstrou que a consulta compartilhada pode ser considerada uma ferramenta importante para a integralidade, visto que é capaz de disparar, movimentar e produzir intervenções com diferentes saberes provenientes da equipe de profissionais envolvidos no cuidado das usuárias.

DESCRITORES: Humanização; Assistência Integral à Saúde; Equipe Multiprofissional.

\section{REFERÊNCIAS}

Brasil. Ministério da Saúde. Secretaria de Atenção à Saúde. Departamento de Ações Programáticas Estratégicas. Política nacional de atenção integral à saúde da mulher: princípios e diretrizes / Ministério da Saúde, Secretaria de Atenção à Saúde, Departamento de Ações Programáticas Estratégicas. - Brasília: Ministério da Saúde, 2004.

Brasil. Ministério da Saúde. Secretaria de Atenção à Saúde. Departamento de Atenção Básica. Estratégias para o cuidado da pessoa com doença crônica / Ministério da Saúde, Secretaria de Atenção à Saúde, Departamento de Atenção Básica. - Brasília: Ministério da Saúde, 2014. 


\section{RELATO DE EXPERIÊNCIA: CONTATO PELE A PELE NO PUERPÉRIO IMEDIATO}

Rosiane Pereira Batista*, Ana Vanessa Deffaccio Rodrigues, Maria Aparecida Moreira.

*Autarquia Municipal de Saúde de Apucarana-AMS, Apucarana-PR, e mail: rosi.batista.br@gmail.com

INTRODUÇÃO: Nos últimos anos, o aleitamento materno no Brasil tem sido alvo de muito interesse dos gestores de saúde no planejamento de políticas e projetos na área materno infantil, na perspectiva de aumentar na prática a amamentação no país. A Iniciativa Hospital Amigo da Criança recomenda os dez passos para o sucesso do aleitamento materno. Destacando o quarto passo, que consiste em colocar os bebês em contato pele a pele com suas mães imediatamente após o parto, por no mínimo uma hora, encorajando-as a reconhecer quando seus bebês estão prontos para serem amamentados. Assegurar o contato pele a pele, deve ser uma prática estimulada e garantida em todos os nascimentos saudáveis de forma contínua. OBJETIVO: Relatar a experiência da residente em Enfermagem Obstétrica no contato pele a pele no período de puerpério imediato em uma maternidade do Norte do Paraná. METODO: Trata-se de um estudo de natureza descritiva tipo relato de experiência. O local escolhido é o setor de alojamento conjunto de uma maternidade do Norte do Paraná, nos anos de 2018 e 2019, conforme calendário de prática do Programa de Residência Profissional em Enfermagem Obstétrica da Autarquia Municipal de Saúde de Apucarana-PR. RESULTADOS: Na atuação diária, na rotina do serviço descrito, o recém-nascido a termo assim que nasce é apresentado à mãe e após é levado para o berço aquecido para avaliação pediátrica. Em seguida, permanece com a mãe no contato pele a pele por aproximadamente duas horas, nesse período o recém-nascido está bem ativo e o profissional de enfermagem, nesse momento, atua para garantir o suporte e incentivo quanto ao aleitamento materno. Na prática, é possível observar que o contato pele a pele tem proporcionado um maior vínculo entre o binômio, favorecendo a promoção do aleitamento materno precocemente. Percebe-se que é importante uma assistência que possibilite orientações oportunas em relação à amamentação, tal como, esclarecimento de dúvidas sobre posição e pega correta, possíveis dificuldades que surgem nesse período, reforçar a essa puérpera que seu leite é suficiente e garantir ao seu bebê tudo que ele precisa. Portanto, a atuação do profissional pode ser decisiva na continuidade desse processo, por meio de uma orientação consistente, para obter sucesso e promover a manutenção saudável do aleitamento materno. CONCLUSÃO: O contato pele a pele realizado na maternidade é capaz de fortalecer o vínculo entre mãe filho, tornando mais positiva a experiência da amamentação, mostrando o quanto a assistência de enfermagem contribui em todo o processo do ciclo gravídico-puerperal. A atuação do profissional comprometida, visando suporte e apoio no puerpério, fase de grande descobertas e fragilidades, podem promover uma manutenção e sucesso no aleitamento materno.

DESCRITORES: Período Pós-Parto; Aleitamento Materno; Cuidados de Enfermagem.

\section{REFERÊNCIAS}

HERGESSELL, N.M.; LOHMANNLL, P.M. Aleitamento Materno na Primeira hora após o parto. Univates, Lajeado/RS, 2017. 
SANTOS, L. M. et al.Vivenciando o contato pele a pele com o recém-nascido no pósparto como um ato mecânico. Revista Brasileira de Enfermagem. V. 67, n. 2, p: 202207, 2014. 


\section{RELATO DE EXPERIÊNCIA: EDUCAÇÃO EM SAÚDE PARA PREVENÇÃO DE CANCÊR DE COLO DE ÚTERO}

Letícia Yumi Girdosek*, Wellington Garcia Siqueira, Kawany de Paula Lima, Keli Regiane Tomeleri da Fonseca Pinto

*Universidade Estadual de Londrina, Londrina- PR, e mail: leh yumii@hotmail.com

INTRODUÇÃO: De acordo com o Instituto Nacional de Câncer, o câncer de colo do útero é o terceiro tipo de neoplasia que acomete mulheres no Brasil, mantendo-se com um índice de mortalidade crescente nos últimos anos. A causa mais frequente para o desenvolvimento deste câncer é pela infecção persistente do Papilomavírus Humano HPV. Como prevenção para este acometimento deve-se realizar exames periódicos, o Papanicolau, e a educação em saúde pelos profissionais capacitados. OBJETIVO: Relatar a experiência de estudantes da graduação na ação em saúde realizada na campanha do Outubro Rosa, mês de conscientização do desenvolvimento de câncer em mulheres. MÉTODOS: Trata-se de um estudo do tipo relato de experiência que descreve a percepção de estudantes de enfermagem em relação a educação em saúde realizada em uma Unidade Básica de Saúde na região Leste de Londrina/Paraná, no mês de Outubro de 2018. Durante a ação foram expostos materiais para conscientização sobre a saúde da mulher; dentre os temas abordados foram passadas orientações quanto a prevenção do câncer de colo do útero através de demonstrações em protótipos sobre como é realizado o exame, alterações encontradas, além de dados e informações como causa, fatores de risco, sintomas e diagnósticos. RESULTADOS: Foi percebido a falta de informação da maioria das mulheres quanto aos fatores predisponentes, formas de prevenção e importância da realização do exame periódico. A partir disso, foi orientado a ficarem atentas aos sinais e sintomas para que buscassem serviço de saúde caso houvessem alterações. Demonstrou-se interesse por parte das mulheres abordadas na ação, que relataram a importância e a falta de mais ações que tragam conhecimento de prevenção para a população. CONCLUSÃO: Sabe-se que as ações em saúde são de grande importância para a comunidade, pois proporciona qualidade de vida e reduz o ciclo do processo de adoecimento, sendo essa uma das competências do profissional de enfermagem. Conclui-se que a ação atingiu os objetivos propostos, sanando duvidas e incentivando a adesão na realização dos exames preventivos e diagnósticos, confirmando-se pelos relatos.

DESCRITORES: Educação em Saúde; Câncer de Colo do Útero; Prevenção; Enfermagem.

\section{Referências:}

OLIVEIRA, W. W. A importância das ações de promoção da saúde realizadas pelo enfermeiro na equipe de saúde da família. Universidade Federal de Minas Gerais. Faculdade de Medicina. Núcleo de Educação em Saúde Coletiva. Conselheiro Lafaiete, 2011. 37f.Monografia (Especialização em Atenção Básica em Saúde da Família). 


\section{SÍFILIS CONGÊNITA DECORRENTE DE REINFECÇÃO DA GESTANTE DEVIDO À NÃO ADESÃO DO PARCEIRO AO TRATAMENTO}

Eliseth Krupa Almeida*, Juliana Sousa de Almeida, Renata Portero Wielganczuk, Natália Carolina Rodrigues Colombo

*Universidade Estadual de Londrina, Londrina-PR, e mail: eliseth.enfermagem@hotmail.com

INTRODUÇÃO: A Sífilis é uma Infecção Sexualmente Transmissível causada pela bactéria Treponema pallidum. Pode ser transmitida por contato sexual (oral, vaginal ou anal) desprotegido ou por transmissão vertical (da mãe para o feto) durante a gestação. O tratamento de primeira escolha tanto para a gestante como para o seu parceiro é a penicilina e o esquema de dosagem varia de acordo com a evolução da infecção. Contudo há uma certa resistência ao tratamento por parte principalmente do parceiro o que acaba por ocasionar a reinfecção da gestante, podendo ainda ocorrer a infecção do feto e como consequência a sífilis congênita. Vale ressaltar que o termo "reinfecção" é quando a gestante é adequadamente tratada, mas o parceiro não é tratado, e ocorre um novo contato sexual, impedindo com que a cadeia de transmissibilidade seja findada, levando a exposição da gestante e feto a Sífilis. Esta por sua vez, dependendo de qual período gestacional acometeu o feto, poderá causar alterações estruturais, visuais e/ ou neurológicas, o que acarreta maiores despesas ao sistema de saúde e desgaste emocional à família. Nesse contexto, o papel da enfermagem se mostra fundamental durante as consultas de pré-natal visando a educação em saúde para a prevenção, proteção e recuperação da saúde da gestante, do parceiro e do recém-nascido. OBJETIVO: Descrever a experiência de residentes de enfermagem obstétrica no atendimento pré-natal e puerperal em uma Unidade Básica de Saúde em Londrina-PR à uma puérpera portadora de sífilis e ao recém-nascido diagnosticado com sífilis congênita. MÉTODO: Trata-se de um relato de experiência sobre a prática vivencial de enfermeiras residentes na realização de consulta pré-natal e puerperal em uma Unidade Básica de Saúde em Londrina-PR. RESULTADOS: Durante as consultas de pré-natal as residentes realizam o acolhimento às gestantes e seus acompanhantes por meio da consulta de enfermagem; checam e atualizam o esquema vacinal; encaminhamento odontológico; orientações nutricionais; realização de Testes Rápidos para sífilis, HIV e Hepatite B e solicitam demais exames relacionados ao ciclo gravídico, mas, nem toda gestante e/ou seu parceiro aderem ao tratamento, expondo-se a si mesmos e o feto a complicações no decorrer da gestação e ciclo de vida. CONCLUSÃO: A atuação do enfermeiro na solicitação, interpretação e acompanhamento de resultado de exames realizados no pré-natal possibilita a prevenção e tratamento de doenças associadas à gestação que podem também acometer o feto. Assim, é de extrema relevância o acompanhamento dos resultados e da adesão ao tratamento e caso o mesmo não esteja sendo realizado corretamente por parte da gestante e seu parceiro, deve-se optar pela busca ativa e reiniciar o ciclo de tratamento e seguimento para verificar eficácia do tratamento.

DESCRITORES: Enfermagem Obstétrica; Sífilis Congênita; Gestante.

\section{REFERÊNCIA}

Londrina, Secretaria Municipal de Saúde. Abordagem do Hiv/Aids e outras infecções sexualmente transmissíveis na Atenção Básica (AB). Londrina, 2016. 


\section{A VIOLÊNCIA OBSTÉTRICA REPRESENTADA NO COTIDIANO INSTITUCIONAL: UMA REVISÃO INTEGRATIVA}

Debora Gonçalves Marrezi*, Andressa Midori Sakai, Danieli Juliani Garbuio Tomedi, Franciely Midori Bueno de Freitas, Lia Juliane Korzune, Mariana Dias Esteves Tamiozzo.

*Universidade Pitágoras Unopar, Londrina-PR, e mail: debora.marrezi@kroton.com.br;

INTRODUÇÃO: A violência, habitualmente, constitui um problema social grave e, dentro deste cenário de representações de atos violentos, destaca-se a violência obstétrica. Desde o ano 2000, o Ministério da Saúde, preconiza a adoção de boas práticas na assistência ao parto com o intuito de melhorar a qualidade do cuidado ofertado às mulheres, nas instituições. Contudo, a institucionalização do parto, trouxe através da reprodução das desigualdades nas relações de poder presentes no espaço social dos serviços de saúde, a violência obstétrica institucional. Embora importantes, as regras organizacionais configuram uma assistência obstétrica que desfavorece a autonomia, respeito e dignidade das mulheres. OBJETIVO: Identificar a produção científica acerca da revisão integrativa da literatura sobre a violência institucional obstétrica, e apresentar as principais evidências encontradas nos artigos selecionados. MÉTODO: Os dados foram adquiridos através da seleção de artigos nas bases: MedLine, LILACS; SciELO e Biblioteca Virtual em Saúde. A amostra foi composta por 9 artigos publicados entre os anos de 2010 e 2018. RESULTADOS: Na discussão, primeiramente, aborda-se o conceito de violência obstétrica e sua ocorrência na assistência. Em sequência, são apresentadas as interfaces do fenômeno com reflexões relacionadas à concepção dos diferentes atores envolvidos, à institucionalização, à invisibilidade e à banalização do evento. Por fim, são apresentadas as estratégias de enfrentamento perpassando pela formação acadêmica, pela conscientização das mulheres, pelas propostas de mobilização social, pela construção de políticas públicas e leis. CONCLUSÃO: A violência obstétrica retrata uma violação dos direitos humanos e um grave problema de saúde pública. Conclui-se que esta pesquisa pode contribuir para a sensibilização no processo de mudança das práticas violentas. A partir da identificação dos fatores associados à ocorrência de violência obstétrica, é possível intervir de forma diretiva e possibilitar o incentivo às instituições para implementação de práticas de ensino humanizado e melhorias na qualidade dos serviços de saúde pública.

DESCRITORES: Violência contra a Mulher; Mulheres; Obstetrícia; Parto Obstétrico; Exposição à Violência; Gravidez.

\section{REFERÊNCIAS}

DINIZ, S. G.; SALGADO, H. O.; ANDREZZO, H. F. A.; CARVALHO, P. G. C.; CARVALHO, P. C. A.; AGUIAR, C. A. et al. Violência obstétrica como questão para a saúde pública no Brasil: origens, definições, tipologia, impactos sobre a saúde materna, e propostas para sua prevenção. Revista Brasileira de Crescimento Desenvolvimento Humano. v. 25, n. 3, p. 377-184, 2015.

BRASIL. Cadernos HumanizaSUS - Volume 4: Humanização do parto e do nascimento. Brasília, DF: UECE/ Ministério da Saúde. 2014. Acesso em 20 de maio, 2019 , em 
Anais da VI Mesa Redonda de Mortalidade Materna e II Simpósio de Enfermagem

Obstétrica,2019;09-67

http://www.redehumanizasus.net/sites/default/files/caderno humanizasus v4 humaniz acao parto.pdf

MILBRATH, V. M. et al. Vivências maternas sobre a assistência recebida no processo de parturição. Escola Anna Nery, n. 14, n. 2, p. 462-467, 2010

PASCHE D. F., VILELA, M. E. A., \& MARTINS, C. P. Humanização da atenção ao parto e nascimento no Brasil: pressuposto para uma nova ética na gestão e no cuidado. Revista Tempus Actas Saúde Coletiva. v. 4, n. 4, p. 105-117, 2010. http://dx.doi.org/10.18569/tempus.v4i4.838

Rede Parto do Princípio. Violência Obstétrica "Parirás com dor" - Dossiê elaborado para a CPMI da Violência Contra as Mulheres. Brasília, DF: Senado Federal. 2012. Acesso em 18 de maio, 2019, em https://www.senado.gov.br/comissoes/documentos/SSCEPI/DOC\%20VCM\%20367.pdf

SANFELICE, C., ABBUd, F., PREGNOLATTO, O., SILVA, M.; SHIMO, A. Do parto institucionalizado ao parto domiciliar. Revista Rene. v. 15, n. 2, p. 362-370, 2014. doi: 10.15253/2175-6783.2014000200022

SERRUYA, S. J., CECATTI, J. G., LAGO, T. G. O Programa de Humanização no Prénatal e Nascimento do Ministério da Saúde no Brasil: resultados iniciais. Cadernos Saúde Pública. v. 20, n. 5, p. 1281-1289, 2004. http://dx.doi.org/10.1590/S0102$\underline{311 \times 2004000500022}$

SODRÉ, T. M; LACERDA, R. A. O processo de trabalho na assistência ao parto em Londrina-PR. Revista da Escola de Enfermagem da USP, v. 41, n. 1, p. 82-9, 2007.

VARGAS, P. B. et al. A assistência humanizada no trabalho de parto: percepção das adolescentes. Revista de Pesquisa Cuidado é Fundamental Online, v. 6, n. 3, p. 10211035, 2014.

VENTURI JUNIOR G, AGUIAR JM, HOTIMSKY SN. A violência institucional no parto em maternidades brasileiras: uma análise preliminar de dados da pesquisa de opinião pública Mulheres brasileiras e gênero nos espaços público e privado - 2010. In: 7o Congresso Brasileiro de Enfermagem Obstétrica e Neonatal; 2011; Belo Horizonte, Brasil. Belo Horizonte: Associação Brasileira de Obstetrizes e Enfermeiros Obstetras; 2011. p. 1-6. 


\section{ASSISTÊNCIA DE ENFERMAGEM DURANTE O TRABALHO DE PARTO: MÉTODOS NÃO FARMACOLÓGICOS PARA ALÍVIO DA DOR}

Debora Gonçalves Marrezi*, Andressa Midori Sakai, Danieli Juliani Garbuio Tomedi, Franciely Midori Bueno de Freitas, Lia Juliane Korzune, Mariana Dias Esteves Tamiozzo

*Universidade Pitágoras Unopar, Londrina-PR, e mail: debora.marrezi@kroton.com.br

INTRODUÇÃO: A realidade obstétrica brasileira apresenta estatísticas ainda divergentes das recomendadas pela Organização Mundial de Saúde e pelo Ministério da Saúde no que diz respeito ao número de cesáreas e às intervenções realizadas durante o trabalho de parto. Estudos sugerem que isso se deve a uma cultura cesarista, pouco humanizada e institucionalizada. Aliada a isso, a falta de orientações adequadas e acompanhamento pré-natal deficitário, fazem com que muitas mulheres associem os partos vaginais exclusivamente à dor e sofrimento. A fim de humanizar o atendimento à gestante e parturiente, pesquisadores realizam estudos e métodos alternativos para minimizar a dor do parto e extinguir esse estigma em relação aos tipos de parto. Ao mesmo tempo, observa-se a necessidade de capacitar os profissionais para que conheçam tais métodos, os apresentem às gestantes esclarecendo seus riscos e benefícios e permitindo que decidam ou não por utiliza-los. OBJETIVO: Identificar o que a literatura nacional apresenta sobre os métodos não farmacológicos mais eficazes para alívio da dor durante o trabalho de parto e investigar como tem sido a assistência de enfermagem com foco na analgesia e levando em consideração as especificidades do período gestacional. MÉTODO: Trata-se de uma revisão bibliográfica, cuja base de referências se deu através de livros didáticos da área e manuais técnicos do Ministério da Saúde, além de artigos da Biblioteca Virtual de Saúde utilizando-se os descritores "dor de parto"; "enfermagem", "humanização", "analgesia" e "parto humanizado". Foram selecionados artigos completos disponíveis na plataforma, idioma português, com período de publicação entre 2000 e 2018 . RESULTADOS: Os métodos não farmacológicos para alívio da dor constituem alternativas seguras, pois não utilizam medicamentos ou drogas, possuindo menos contraindicações ou efeitos colaterais. Dentre os métodos não farmacológicos para alívio da dor citados na literatura, encontramos a presença de acompanhante de escolha da mulher; adoção de posturas diversas e deambulação; banhos quentes de aspersão ou imersão; massagens com uso de gelo, compressas quentes, acupuntura, hipnose e aroma terapia, além de técnicas de respiração e de vocalização. O enfermeiro obstetra enquanto profissional apto, deve informar a gestante sobre a evolução do trabalho de parto e esclarecer as condutas adotadas, as opções disponíveis para analgesia, sempre com foco no bem-estar materno e fetal. CONCLUSÃO: As vantagens da analgesia durante o trabalho de parto são inúmeras, pois, uma parturiente sem dor é mais colaborativa, atribuindo à experiência uma maior tranquilidade e caráter mais prazeroso. Há diversos métodos alternativos que podem e devem ser indicados às pacientes, sendo inclusive mais seguros que partos cirúrgicos, entretanto, no Brasil, ainda são pouco difundidos, apontando a necessidade de capacitar adequadamente os profissionais para sua promoção junto às parturientes, além do esclarecimento às pacientes sobre o risco de intervenções desnecessárias garantindo que o atendimento seja humanizado, mas acima de tudo, seguro. 


\section{Obstétrica,2019;09-67}

DESCRITORES: Dor do parto; Enfermagem; Parto Humanizado.

\section{REFERÊNCIAS:}

ALMEIDA, N.A.M. et al. Concentração plasmática do hormônio adrenocorticotrófico de parturientes submetidas a métodos não farmacológicos de alívio de ansiedade e dor do parto. Revista Latino-americana de Enfermagem. v.13, n2, p.223-238, 2005.

ALMEIDA, J.M.; ACOSTA, L.G.; PINHAL, M.G.. Conhecimento das puérperas com relação aos métodos não farmacológicos de alívio da dor do parto. Revista Mineira de Enfermagem. v.19, n.3, p.711-717, 2015.

BASTON, H.; HALL, J. O Parto. 1aㅡ ed. Série Enfermagem Essencial. Rio de Janeiro: Elsevier, 2010.

BEZERRA, M.G.A.B.; CARDOSO, M.V.L.M.L. Fatores culturais que interferem nas experiências das mulheres durante o trabalho de parto e parto. Revista Latinoamericana de Enfermagem. v.14, n.3, p.414-421, 2006.

BIO, E.; BITTAR, R.E.; ZUGAIB, M. Influência da mobilidade materna na duração da fase ativa do trabalho de parto. Revista Brasileira de Ginecologia e Obstetrícia. v.28, n.13, p.671-679, 2006.

BUENO, J.V. Avaliação da intensidade e característica da dor no trabalho de parto e a ação do misoprostol. 2006. Dissertação (Mestrado em Enfermagem em Saúde Pública) - Escola de Enfermagem de Ribeirão Preto, Universidade de São Paulo, Ribeirão Preto, 2006.

BRUGGEMANN, O.M.; PARPIUNELLI, M.A.; OSIS, M.J.D. Evidências sobre o suporte durante o trabalho de parto/parto: uma revisão da literatura. Cadernos de Saúde Pública. v.21, n.5., 2005.

COFEN, Resolução Cofen nำ0516/2016. Normatiza a atuação e a responsabilidade do Enfermeiro, Enfermeiro Obstetra e Obstetriz na assistência às gestantes, parturientes, puérperas e recém-nascidos nos Serviços de Obstetrícia, Centros de Parto Normal e/ou Casas de Parto e outros locais onde ocorra essa assistência; estabelece critérios para registro de títulos de Enfermeiro Obstetra e Obstetriz no âmbito do Sistema Cofen/Conselhos Regionais de Enfermagem, e dá outras providências.

DAVIM, R.M.B.; TORRES, G.V.; DANTAS, J.C. Representação de parturientes acerca da dor de parto. Revista Eletrônica de Enfermagem, Goiânia, v.10, n.1, p.100-109, 2008.

DAVIM, R.M.B. et al. Banho de chuveiro como estratégia não farmacológica no alívio da dor de parturientes. Revista Eletrônica de Enfermagem, Goiânia, v.10, n.3, p.600609, 2008.

NAIME, F.F.. Manual de Tratamento da Dor. $2^{\underline{a}}$ ed. Rio de Janeiro: Manole, 2013.

PINHEIRO, A.L.U. et al. Avaliação e manejo da dor aguda: revisão integrativa. J Nurs Healt, Pelotas, v.4, n.1, p.77-89, 2014 


\section{Obstétrica,2019;09-67}

POTTER, P.A.; PERRY, A.G. Fundamentos de enfermagem. 5ㄹed. Rio de Janeiro: Guanabara Koogan, 2004.

REZENDE FILHO, J.; MONTENEGRO, C.A.B. Obstetrícia Fundamental. 13ª ed. Rio de Janeiro: Guanabara Koogan, 2014.

SALVETTI, M.G.; PIMENTA, C.A.M. Dor crônica e a crença de auto-eficácia. Revista da Escola de Enfermagem da USP, Ribeirão Preto, v.41, n.1, p.135-140, 2007.

SILVA, F.M.B.; OLIVEIRA, S.M.J.V. O efeito do banho de imersão na duração do trabalho de parto. Revista da Escola de Enfermagem da USP, Ribeirão Preto, v.40, n.1, 2006.

SOUSA, F.A.E.F.S. Dor: o quinto sinal vital. Revista Latino-Americana de Enfermagem. v. 10, n. 3, p. 446-447, 2002. 
Anais da VI Mesa Redonda de Mortalidade Materna e II Simpósio de Enfermagem

Obstétrica,2019;09-67

\section{O IMPACTO DA RETIRADA DO TERMO "VIOLÊNCIA OBSTÉTRICA" NO ENSINO}

Márcia Aparecida dos Santos Silva Canario*, Daniele Bernardi da Costa, Danieli Juliani Garbuio Tomedi, Lia Juliane Korzune, Natalia Shinkai Binotto $\begin{array}{llll}\text { *Universidade } \quad \begin{array}{c}\text { Pitágoras } \\ \text { marcia.canario@kroton.com.br }\end{array} & \text { Unopar, Londrina-PR, } & \text { e } & \text { mail: }\end{array}$

INTRODUÇÃO: No ano de 2019 o Ministério da Saúde surpreendeu com a abolição do termo "violência obstétrica" por considerar inadequado seu uso na assistência prestada à mulher. No Brasil, a luta pela melhoria da assistência ao parto e nascimento vem sendo travada ao longo dos anos, e teve sua ampliação através da criação da Programa de Assistencial Integral á Saúde da Mulher em 1984, da incorporação do Programa de Humanização do Pré-Natal e Nascimento no ano de 2000, Rede Cegonha em 2011 e Rede Mãe Paranaense em 2012. Todos esses programas de saúde visam o progresso e humanização no âmbito do trabalho de parto, parto e nascimento, portanto, a retirada do termo "violência obstétrica" traz inúmeros prejuízos estruturais e sociais, assim como desvaloriza o ensino humanizado e qualificado na assistência obstétrica. OBJETIVO: Identificar o termo "violência obstétrica" como tema de ensino. MÉTODO: O estudo consiste em uma revisão da literatura nacional sem delimitação de tempo, em maio de 2019. A base de dados utilizada para essa pesquisa foi a LILACS (Literatura Latino-Americana e do Caribe em Ciências da Saúde). Para a inclusão na pesquisa foram considerados artigos indexados ao banco de dado citado, em concordância com as palavras-chaves escolhidas: violência obstétrica e ensino. No uso dos termos "violência" and "obstétrica" foram recuperados 79 artigos, após o ajuste dos termos para "violência" and "obstétrica" and "ensino" foram identificados quatro artigos, dentre os quais três estavam possuíam texto completo disponível, sendo selecionados para o estudo. Em concordância com a Resolução № 466 de 2012 do Conselho Nacional de Saúde não foi necessária à submissão do mesmo para apreciação por Comitê de Ética em Pesquisa. RESULTADOS: Os artigos reportam a importância da humanização na atenção obstétrica, evidenciada pelas recomendações da Organização Mundial da Saúde, assim como, apontam a violência obstétrica como uma violação dos direitos humanos. Refletem que a inserção de disciplinas com conteúdo de humanização vem ocorrendo em cursos da área da saúde, no entanto, o desinteresse do aluno aliado ao distanciamento da prática profissional, tem contribuído para formação pouco humanizada e tecnicista, refletindo na baixa qualidade da assistência nos serviços de saúde. $\mathrm{O}$ uso da mulher como instrumento de aprendizagem sem recomendação clínica foi apontado nos estudos, sendo a episiotomia de rotina a principal intervenção obstétrica desnecessária atribuída a prática do ensino. As mulheres que dependem do atendimento em instituições de ensino como "hospital-escola" estão sujeitas a práticas dolorosas, desnecessárias conduzidas por profissionais inexperientes. A excessiva medicalização do parto tornouse um evento obstétrico, reforçado pelo poder cultural de dor e sofrimento associado ao parto e nascimento contribuem para submissão da mulher aos profissionais de saúde. CONCLUSÃO: A violência obstétrica pode ser sentida no amplo aspecto da palavra desde a infraestrutura precária a resistência ao ensino da prática humanizada, aliado a objeção do governo em compartilhar das medidas baseadas em evidências reconhecidas nacionalmente e internacionalmente como promotoras do cuidado que LONDRINA, 2019. 


\section{Obstétrica,2019;09-67}

elevam a qualidade da assistência obstétrica prestada e são essenciais no processo de ensino e aprendizagem.

DESCRITORES: Saúde da Mulher; Educação em Enfermagem; Parto Humanizado.

\section{REFERÊNCIAS}

SOUZA, A. B. et al. Fatores associados à ocorrência de violência obstétrica institucional: uma revisão integrativa da literatura. Revista Ciência Médica. v. 25, n. 3, p.115-128, 2016.

ANDRADE, P. O. N. et al. Fatores associados à violência obstétrica na assistência ao parto vaginal em uma maternidade de alta complexidade em Recife, Pernambuco. Revista Brasileira de Saúde Materno Infantil. v. 16, n. 1, p. 29-37, 2016.

FIGUEIRÊDO, N. M. A.; TYRRELL, M. A. R.; CARVALHO, V.; LEITE, J. L. Indicadores de cuidados para o corpo que pro-cria: ações de enfermagem no pré-trans e pós-parto - uma contribuição para a prática de enfermagem obstétrica. Revista Latinoamericana Enfermagem. v. 12, n. 6, p. 905-912, 2004. 


\title{
36. PRINCIPAIS DETERMINANTES DE NEAR MISS MATERNO QUE LEVAM PUÉRPERAS A UMA UTI OBSTÉTRICA: REVISÃO INTEGRATIVA
}

\author{
Murilo Venancio Gaiowski, Giovana Diniz Dutra, Thaíse Castanho da Silva \\ *Centro Universitário Filadélfia-UniFil, Londrina-PR, e mail: \\ murilovenancio@hotmail.com
}

INTRODUÇÃO: As complicações maternas entram em uma categoria abrangente de uma recompilação de condições clínicas que incluem doenças podendo ameaçar a vida da mulher, este podendo iniciar durante a gestação, no período interpartal e após os 42 dias de seu puerpério. O Ministério da Saúde tem como meta a redução da mortalidade materna de 100 mil para 30 mil nascidos vivos até 2030 . O termo near miss é apontado como uma sobrevivência da mulher que quase morreu devido a complicações graves decorrentes da gravidez, do parto ou no período puerperal de 42 dias após o parto. Ocorrências obstétricas geralmente podem se tornar fatais, tendo ou não um risco de morte, terminando assim em um caso de near miss materno, caso sobreviva, ou morte materna. OBJETIVO: avaliar quais são os principais determinantes de near miss materno em puérperas em uma UTI obstétrica. MÉTODO: O presente estudo trata-se de uma revisão integrativa da literatura, a qual é considerada método de pesquisa que possibilita a busca, a avaliação crítica e a síntese do estado do conhecimento sobre determinado assunto. $O$ estudo teve a seguinte questão norteadora: quais são os principais determinantes de near miss materno em puérperas em uma Unidade de Terapia Intensiva Obstétrica? A busca na literatura científica foi realizada para o período entre os anos 2015 a 2018, em inglês e português, em três importantes bases de dados BVS - BIREME: LILACS, MEDLINE e BDENF. Foram excluídos artigos de revisão e artigos on-line não disponíveis na íntegra. Desta forma, na busca tivemos 25 artigos como resultado e foram excluídos 18 artigos por não se enquadrar no tema. Para análise do conteúdo dos artigos foi utilizado um instrumento de coleta de dados, contemplando as seguintes informações: ano de publicação, abordagem metodológica e resultados com enfoque no near miss materno. A análise dos dados ocorreu de forma organizada e crítica, à medida que se realizou leitura aprofundada dos conteúdos, buscando esclarecimentos a respeito do tema e propondo problematizações. RESULTADOS: De forma geral os estudos apresentaram como objetivo comparar as incidências dos critérios de near miss materno, a prevalência das complicações, o perfil clínico e epidemiológico das pacientes e avaliar os casos e fatores determinantes da morbimortalidade materna. Mostra-se que os casos de near miss materno ocorrem pela complicação de hemorragia e infecções. Observou-se também que houve maior frequência de casos de near miss com distúrbios hipertensivos, seguido de sepse grave, de hemorragia grave e complicações pulmonares. CONCLUSÃO: Com a realização deste estudo foi possível compreender os principais determinantes de near miss materno que levam puérperas a uma UTI obstétrica. Diante da baixa produção científica sobre esta temática em periódicos brasileiros sobre near miss materno, recomenda-se a ampliação de estudos que enfoquem esta temática, em especial nas revistas nacionais. Os resultados encontrados podem vir a auxiliar no estabelecimento de políticas públicas e estratégias na assistência com 0 intuito de intervir significativamente na problemática da morbidade e mortalidade materna no Brasil. 


\section{Obstétrica,2019;09-67}

DESCRITORES: Near Miss; Morte Materna; UTI.

\section{REFERÊNCIAS}

BRASIL. Ministério da Saúde. Brasília, 2018. Disponível em: http://portalms.saude.gov.br/noticias/agencia-saude/43325- <ministerio-da-saudeinveste-na-reducao-da-mortalidade-materna>.

ORGANIZAÇÃO MUNDIAL DA SAÚDE (OMS). Avaliação da qualidade do cuidado nas complicações graves da gestação. [Site]. 2011. Disponível em: $<$ https://www.paho.org/clap/index.php?option=com_docman\&view=d ownload\&category_slug=salud-de-mujer-reproductiva-materna-yperinatal\&alias=414avaliacao-da-qualidade-do-cuidado-nascomplicacoes-graves-da-gestacao-aabordagem-do-near-miss- 4\&ltemid=219\&lang=es $>$.

RUDEY, E.L; CORTEZ, L.E.R; YAMAGUCHI, M.U. Identificação de near miss materno em unidade de terapia intensiva. Revista Saúde e Pesquisa, v. 10, n. 1, p. 145-155, jan./abr. 2017 - ISSN 1983-1870 - e-ISSN 2176-9206. 


\section{O CUIDADO CENTRADO NA FAMÍLIA NA UNIDADE DE TERAPIA INTENSIVA NEONATAL: FOCO NO MÉTODO CANGURU}

Lorena Maria Fernandes da Silva*, Edilaine Giovanini Rossetto.

*Universidade Estadual de Londrina, Londrina-PR, e mail: lorenafernandes.mua@gmail.com

INTRODUÇÃO: O envolvimento da família com um bebê recém-nascido que está dentro de uma unidade de terapia intensiva é fundamental para lhe conferir inúmeros benefícios, que podem se estender para os familiares e até para a equipe profissional da unidade. $O$ método canguru é uma forma excelente de promover esse vínculo, pois a partir deste contato pele a pele os pais desenvolvem uma segurança em oferecer cuidados básicos ao recém-nascido de maneira mais rápida, fácil e sólida. Um dos benefícios do método canguru é a redução da infecção e da hospitalização do recémnascido, além da promoção do aleitamento materno. Entretanto, para que esse cuidado se efetive de maneira precoce e contínua, é preciso a mudança do modelo de atenção para o cuidado centrado na família. OBJETIVO: Relatar a experiência da implantação do método canguru em uma unidade neonatal durante a hospitalização de um recém-nascido. MÉTODOS: As estratégias utilizadas foram diversificadas, considerando que mudanças de paradigma são processos demasiadamente complexos de serem modificados. A partir das evidências científicas sobre os benefícios desse novo método, foram realizados encontros com os médicos, docentes e residentes para sensibilizá-los sobre tal prática. Outras categorias foram reunidas para o envolvimento na implantação do cuidado canguru: enfermagem, fisioterapia, psicologia e serviço social. Além de todas as categorias profissionais envolvidas, os familiares receberam abordagem material educativo, abordagem individual ao nascimento de seus filhos e reuniões semanais com os pais que devem buscar realizar o canguru o maior tempo possível. RESULTADOS: Cartazes foram espalhados por toda a unidade para evidenciar a importância dessa prática, diários maternos foram implementados, a prescrição de enfermagem foi reestruturada e as rotinas da unidade foram revistas para possibilitar a acomodação dos pais continuamente dentro da unidade. Pode-se observar a partir dos relatórios de enfermagem que o método canguru está sendo colocado cada vez mais em prática pela equipe e pelos familiares, porém este deve ser um trabalho contínuo e crescente. CONCLUSÕES: Com esta prática, a família se torna uma peça fundamental nos cuidados prestados ao recémnascido. O método canguru e o cuidado centrado na família andam juntos, um favorecendo o outro. Sendo assim, o método canguru pode ser olhado sob uma nova perspectiva durante a hospitalização de qualquer recém-nascido, além de ser uma maneira de baixo custo e que pode ser feita por qualquer familiar, inclusive pelo pai. É uma forma eficiente e humanizada de aproximar a família e o bebê durante sua hospitalização.

DESCRITORES: Método Canguru; Relação familiar; Enfermagem materno-infantil.

\section{REFERÊNCIAS:}

GONTIJO, T.L.; XAVIER, C.C; FREITAS, M.I.F. Avaliação da implantação do Método Canguru por gestores, profissionais e mães de recém-nascidos. Caderno Saúde Pública, v. 28,n. 5, p. 935-944, 2012. Disponível em 
<http://www.scielo.br/scielo.php?script=sci_arttext\&pid=S0102311X2012000500012\&lng=pt\&nrm=iso >. Acesso em 15 jun. 2019. http://dx.doi.org/10.1590/S0102-311X2012000500012.

BRASIL. Ministério da Saúde. Atenção Humanizada ao Recém-Nascido: Método Canguru - Manual Técnico. Brasília, DF, 2017. 